\title{
Germline polymorphisms (SNPs) to predict toxicity and efficacy in FLOT-treated patients with locally advanced gastroesophageal junction or gastric adenocarcinoma-data from the NeoFLOT study
}

\author{
Christoph Schulz ${ }^{1}$, Wu Zhang ${ }^{2}$, Heinz-Josef Lenz ${ }^{2}$, Jens Neumann ${ }^{3}$, Frank Kullmann ${ }^{4}$, \\ Volker Kunzmann $^{5}$, Martin Fuchs ${ }^{6}$, Volker Heinemann ${ }^{1}$, Julian Walter Holch ${ }^{1 \#}$, Sebastian Stintzing ${ }^{1,2 \#}$ \\ ${ }^{1}$ Department of Medicine III, University Hospital, LMU Munich, Munich, Germany; ${ }^{2}$ Division of Medical Oncology, Norris Comprehensive Cancer \\ Center, Keck School of Medicine, University of Southern California, Los Angeles, CA, USA; ${ }^{3}$ Department of Pathology, University of Munich, \\ Munich, Germany; ${ }^{4}$ Department of Medicine I, Hospital Weiden, Weiden, Germany; ${ }^{5}$ Department of Internal Medicine II, Department of Medical \\ Oncology, University of Würzburg, Würzburg, Germany; ${ }^{6}$ Department of Gastroenterology, Hepatology and GI-Oncology, Hospital Bogenhausen, \\ Munich, Germany \\ Contributions: (I) Conception and design: C Schulz, HJ Lenz, V Heinemann, S Stintzing; (II) Administrative support: C Schulz, W Zhang, J \\ Neumann, JW Holch, S Stintzing; (III) Provision of study materials or patients: C Schulz, F Kullmann, V Kunzmann, M Fuchs, V Heinemann, JW \\ Holch, S Stintzing; (IV) Collection and assembly of data: C Schulz, J Neumann, F Kullmann, V Kunzmann, M Fuchs, S Stintzing; (V) Data analysis \\ and interpretation: C Schulz, W Zhang, HJ Lenz, V Heinemann, JW Holch, S Stintzing; (VI) Manuscript writing: All authors; (VII) Final approval \\ of manuscript: All authors. \\ \#These authors contributed equally to the work. \\ Correspondence to: Dr. Christoph Schulz, MD. Department of Medicine III, University Hospital, LMU Munich, Marchioninistr. 15, 81377 Munich, \\ Germany. Email: chris.schulz@med.uni-muenchen.de.
}

Background: Perioperative treatment is standard of care in Western Europe for locally advanced gastroesophageal cancer (GEC) [gastric and gastroesophageal junction (GEJ) adenocarcinoma]. Predictive markers for toxicity and efficacy prior to start with chemotherapy are desirable, particularly when applying a prolonged neoadjuvant treatment. Here we analyse the impact of previously published SNPs involved in drug metabolism and DNA repair.

Methods: Genomic DNA was isolated from 48 tumor samples of patients treated within the NeoFLOTstudy. In this trial, FLOT (5-FU, leucovorin, oxaliplatin, docetaxel) was administered every two weeks for 6 cycles chemotherapy prior to surgery. Direct DNA sequencing was carried out for rs25487 [Excision Repair Cross-Complementation Group 1 (XRCC1)], rs1805087 [5-methyltetrahydrofolate-homocysteine methyltransferase (MTR)], rs11615 and rs3212986 (both ERCC1), rs1799793 and rs13181 (both ERCC2), rs1801019 [Orotate Phosphoribosyl Transferase (OPRT)] and rs16430del [thymidylate synthase: 6-bpdeletion in the in the $3^{\prime}$ untranslated regulatory region (TS3utrdel)]. Furthermore, thymidylate synthase: 28-bp-tandem repeats in the 5' untranslated region (TS5utr tandem repeat) polymorphism was analysed by Restriction Fragment Length Polymorphism (RFLA). Toxicity was stated according to NCI-CTC version 4.0. For efficacy analysis overall response rate (ORR), progression-free survival (PFS), overall survival (OS), and recurrence-free survival (RFS) were used.

Results: ERCC2 rs1799793 was significantly associated with thrombocytopenia $\geq$ grade 3 ( $\mathrm{P}=0.04)$ and overall hematotoxicity $\geq$ grade $3(\mathrm{P}=0.04)$ while rs 13181 was significantly associated with leukopenia $\geq$ grade $3(\mathrm{P}=0.03)$. Rs11615 of ERCC1 had a predictive value for leukopenia $(\mathrm{P}=0.04)$ and thrombocytopenia $(\mathrm{P}=0.008)$. Rs1805087 of MTR and TS5utr tandem repeat polymorphism were both associated with anemia $(\mathrm{P}=0.04$ and 0.04 , respectively). Concerning non-hematological toxicity, rs 1805087 of MTR was associated with diarrhea $(\mathrm{P}=0.004)$. Regarding treatment efficacy, patients harbouring the minor allele of $\mathrm{C}$ of OPRT rs1801019 obtained a higher ORR and showed a better but statically non-significant prolonged PFS and OS while rs3212986 of ERCC1 was associated with pCR rate $(\mathrm{P}=0.006)$.

Conclusions: For single nucleotide polymorphism (SNPs) of ERCC1/2, MTR and TS tandem repeat we 
could demonstrate the predictive value for toxicity of FLOT in GEC. Furthermore, OPRT rs1801019 might be useful to predict response for neoadjuvant treatment.

Keywords: Gastric cancer; gene polymorphisms; neoadjuvant; oxaliplatin; single nucleotide polymorphism (SNP)

Submitted May 31, 2018. Accepted for publication Oct 19, 2018.

doi: $10.21037 /$ tcr.2018.11.03

View this article at: http://dx.doi.org/ 10.21037/tcr.2018.11.03

\section{Introduction}

Gastric cancer (GC) and adenocarcinoma of the gastroesophageal junction (GEJ) are malignancies associated with poor prognosis in most patients (1-3). Within perioperative therapeutic concepts, neoadjuvant chemotherapy aims to reduce the tumor burden, enhances the probability of R0-resection and is believed to erase occult micrometastasis (4). Since the MAGICtrial, conducted in patients with stage II or III resectable adenocarcinoma of the stomach, GEJ and lower oesophagus clearly demonstrating the benefit from perioperative chemotherapy with three cycles of ECF [epirubicin, cisplatin, 5-fluorouracil (5-FU)] applied before and after surgery (5), perioperative chemotherapy is seen as standard of care for locally advanced GC in Western Europe.

The FLOT regimen has been developed using the well tolerated FLO (5-FU, oxaliplatin) regimen by adding docetaxel. In the perioperative setting, it has shown an increased pathological complete response (pCR) rate when compared to ECF or ECX (epirubicin, cisplatin, capecitabine) (6). Survival data presented on the ASCO meeting 2017 revealed a significantly prolonged progressionfree survival (PFS) and overall survival (OS) of FLOT compared the control arm (median PFS 30 vs. 18 months; $\mathrm{HR}=0.75, \mathrm{P}=0.004$; median $\mathrm{OS} 50$ vs. 35 months, $\mathrm{HR}=0.77, \mathrm{P}=0.012)(7)$.

The NeoFLOT-study addressed the important question whether 6 cycles of preoperative FLOT is safe and efficient (8). As a prolonged neoadjuvant therapy has putatively notable side effects, it would be desirable to predict toxicity and response prior to administering FLOT. Therefore, genes involved in the metabolism or targets of 5-FU, oxaliplatin and docetaxel are the primary objectives in the quest of biomarkers.

In the palliative setting, Goekkurt et al. analysed polymorphisms for the use of 5-FU and cisplatin in thymidylate synthase (TS), methyltetrahydrofolatereductase (MTHFR), glutathione S-transferase pi 1
(GSTP1), Glutathione S-transferase theta 1 (GSTT1), glutathione S-transferase mu 1 (GSTM1), excision repair cross-complementation group 1 (ERCC1) and excision repair cross-complementation group 2 (ERCC2) and was able to describe a favourable TS genotype (9). Furthermore, the same group reported a potential predictive value of several SNPs for the use of FLOT (10). In a Chinese trial of over 100 patients with GC and neoadjuvant platinum-and 5-FU-based chemotherapy, the association with response of SNPs in the genes of MTHFR, dihydropyrimidine dehydrogenase (DPYD), uridine monophosphate synthetase (UMPS) [alias Orotate phosphoribosyl transferase (OPRT)], ERCC1, X-ray repair complementing defective repair in Chinese hamster cells 1 (XRCC1) and others was analysed. Of 13 SNPs in 8 genes, the rs717620 ABCC2-24C>T (ATP binding cassette subfamily B member) polymorphism turned out to be associated with pathological response (11). TS as the primary target of 5-FU and the TS tandem repeat polymorphism (TS5utr tandem repeat) has been previously reported to be of predictive value for toxicity and efficacy in metastatic GC and GEJ cancer patients $(10,12)$. TS expression could be further altered by a SNP within TS5utr tandem repeat resulting in enhanced 5-FU activity and reduced regeneration capability $(10,13)$. Figure S1 schematically depicts the involvement of TS and other genes analysed within the present trial in 5-FU, folate and methionine metabolism.

Moreover, 5-FU is metabolized partly by OPRTmediated phosphorylation (14).

5-methyltetrahydrofolate-homocysteine methyltransferase (methionine synthase) (MTR) catalyzes the final step in methionine biosynthesis and is essential in folate metabolism. A decreased MTR activity leads to lower methionine levels and improves 5-FU activity (15).

For platinum-based chemotherapy numerous polymorphisms have been described to be associated with response and survival $(16,17)$. ERCC1, ERCC2 and XRCC1 are the most frequently investigated genes for germline variants and their association with chemotherapeutic 
efficacy. Being part of the base excision repair (BER) and the nucleotide excision repair (NER) pathway, these enzymes are involved in DNA repair (Figure S2) and communicate platinum resistance both in vitro and in vivo.

Aim of the present analysis in the neoadjuvant setting was to investigate the predictive value of previously published germline polymorphisms assayed in the palliative setting, primarily for toxicity during an escalated neoadjuvant therapy, and secondary for efficacy. Especially against the background of the recent efficacy data of perioperative FLOT, biomarker data derived from a prospective trial might help to discriminate patients who should receive intensive chemotherapy prior to surgery. Here we focused on the impact on toxicity and treatment efficacy of a set of SNPs [rs25487 (XRCC1), rs1805087 (MTR), rs11615 and rs3212986 (both ERCC1), rs1799793 and rs13181 (both ERCC2), rs1801019 (OPRT), rs16430del (TS3utrdel) and TS5utr tandem repeat] in the neoadjuvant setting and with a prolonged FLOT regimen for the treatment of GC and GEJ tumors.

\section{Methods}

\section{Material and patients}

The phase II NeoFLOT-trial tested whether the concept to prolong neoadjuvant chemotherapy cycles prior to surgery in locally advanced GC or cancer of the GEJ is safe and tolerable. Detailed data of the trial has been published before (8). In short, patients with resectable, untreated T3/T4 and/or node-positive locally advanced GC and GEJ adenocarcinoma were included. Eligible patients received six cycles of neoadjuvant FLOT consisting of 5 -FU 2,600 mg/m (24-h infusion), leucovorin $200 \mathrm{mg} / \mathrm{m}^{2}$ (1-h infusion), oxaliplatin $85 \mathrm{mg} / \mathrm{m}^{2}$ (2-h infusion), docetaxel $50 \mathrm{mg} / \mathrm{m}^{2}$ (1-h infusion) every 2 weeks. Chemotherapy was continued until progressive disease (PD), unacceptable toxicity, patients' refusal, physician's decision or until completion of the cycles. Resection included D2lymphadenectomy and was scheduled within 2-6 weeks after the completion of the 6th cycle. Imaging by computed tomography (CT) or magnetic resonance imaging (MRI) of chest and abdomen as well as gastroduodenoscopy and endoscopic ultrasound (EUS) were carried out before the start of the treatment. After three cycles of FLOT, restaging was performed. Patients with $\mathrm{PD}$ were then scheduled to immediate surgery. After six cycles of FLOT, a preoperative restaging was performed with CT or MRI, gastroduodenoscopy and optional EUS. Postoperative imaging was performed every 3 months up to 36 months. The assessment of response to neoadjuvant treatment was defined in analogy to RECIST version 1.1 by reduction of tumor size, number and size of lymph nodes measured. Toxicity and adverse events were graded according to NCICTC (version 4). Resection status (R0/R1) and tumor regression were evaluated by a board-certified pathologist. The per-protocol (PP)-population was defined as completing preoperative chemotherapy and undergoing surgery and comprised 50 patients. All patients had given their written informed consent for the trial and the translational research (ethic committee of the LMU \#252-09). The patient cohort of the present trial consisted of patients of the PP-population of the main trial undergoing surgery and being evaluable for the primary endpoint R0-resection rate. Furthermore, sufficient amount of tissue sample was required. Due to the limited comparability of toxic side effects of patients undergoing less than 5 cycles of FLOT, these patients were excluded beforehand.

SNPs previously published to have value for the prediction of toxicity and/or efficacy of the FLOT regimen were evaluated for the association with pCR rate, overall response rate (ORR), PFS, OS, and recurrence-free survival (RFS). Furthermore, hematological toxicity according to NCICTC version 4.0 grading with anemia, thrombocytopenia, leukopenia, and neutropenia was associated with the respective SNPs. In addition, overall hematotoxicity as composite toxicity was computed as done by others (10) to evaluate the association with any kind of hematotoxicity.

\section{DNA extraction and genotyping}

Tumor samples (pre-and post-therapeutic) of 48 patients were available for DNA analysis. Peritumoral stroma was identified by a board-certified pathologist and was subjected to DNA extraction. The tissue was obtained by manual microdissection from unstained sections coupled with stained scout sections. Genomic DNA was extracted from formalin-fixed paraffin-embedded (FFPE) tissues using the QIAmp Kit (Qiagen, Valencia, CA, USA) according to the manufacturer's protocol. Then, DNA was stored at $-20{ }^{\circ} \mathrm{C}$ until use. PCR products were analyzed using direct sequencing. SNPs that have been previously published with reference primarily to toxicity and secondary to efficacy of the chemotherapeutic agents of the FLOT-regimen in GC and GEJ tumors have been selected. The candidate SNPs were tested using PCR-based direct DNA sequence analysis by ABI 3100A Capillary Genetic Analyzer and Sequencing 
Table 1 SNPs tested on the NEOFLOT cohort

\begin{tabular}{|c|c|c|c|c|c|}
\hline Gene SNP & MAF & Location & Functional class & Forward $(f)$ and reverse $(r)$ primer & Reference \\
\hline rs1801019 & $19 \%$ & $\mathrm{G} / \mathrm{C}$ intron & $\begin{array}{l}\text { Non-synonymous } \\
\text { coding }\end{array}$ & $\begin{array}{l}\text { f: TGTCCAAAATGCTGGAGATTC; } \\
\text { r: TGAGTTCTITGGGTGCTTCC }\end{array}$ & Lee, 2015 (18) \\
\hline \multicolumn{6}{|l|}{ MTR } \\
\hline \multicolumn{6}{|l|}{ ERCC1 } \\
\hline rs11615 & $33 \%$ & T/C upstream & $\begin{array}{l}\text { Regulatory region } \\
\text { variant }\end{array}$ & $\begin{array}{l}\text { f: TGTGGTTATCAAGGGTCATCC; } \\
\text { r: GAGCTCACCTGAGGAACAGG }\end{array}$ & Zhou, 2015 (16) \\
\hline rs3212986 & $30 \%$ & $\mathrm{G} / \mathrm{T}$ & Missense variant & $\begin{array}{l}\text { f: AGTCTCTGGGGAGGGATTCT; } \\
\text { r: AATTCAGAGTCTGGGGAGGAG }\end{array}$ & Xue, 2015 (20) \\
\hline rs1799793 & $19 \%$ & $\mathrm{C} / \mathrm{A}$ & Missense variant & $\begin{array}{l}\text { f: GAGTACCGGCGTCTGGTG; } \\
\text { r: CTGCGAGGAGACGCTATCAG }\end{array}$ & Zhou, 2015 (16) \\
\hline \multicolumn{6}{|l|}{ XRCC1 } \\
\hline rs25487 & $26 \%$ & $\mathrm{~T} / \mathrm{C}$ & Missense variant & $\begin{array}{l}\text { f: CCCCAAGTACAGCCAGGTC; } \\
\text { r: CAGTCTGACTCCCCTCCAGA }\end{array}$ & $\mathrm{Wu}, 2014(21)$ \\
\hline \multicolumn{6}{|l|}{ TS3utrdel } \\
\hline rs16430del & $37 \%$ & del[TAAAGT] & 6-bp-deletion & $\begin{array}{l}\text { f: CAAATCTGAGGGAGCTGAGT; } \\
\text { r: CAGATAAGTGGCAGTACAGA }\end{array}$ & $\begin{array}{l}\text { Stoehlmacher, } 2004 \text { (22); } \\
\text { Ulrich, } 2000 \text { (23) }\end{array}$ \\
\hline
\end{tabular}

SNP, single nucleotide polymorphism; MAF, minor allele frequency; UMPS, uridine monophosphate synthetase; OPRT, Orotate Phosphoribosyl Transferase; G, guanine; C, cytosine; MTR, 5-methyltetrahydrofolate-homocysteine methyltransferase; A, adenine; ERCC1, Excision Repair Cross-Complementation Group 1; T, thymine; ERCC2, Excision Repair Cross-Complementation Group 2; XRCC1, X-ray repair complementing defective repair in Chinese hamster cells 1; TS3utrdel, thymidylate synthase: 6-bp-deletion in the 3' untranslated regulatory region; bp, base pair; TS5utr tandem repeat, thymidylate synthase: 28 -bp-tandem repeats in the $5^{\prime}$ untranslated region; NA, not available.

Scanner v1.0 (Applied Biosystems, Waltham, MA, USA). The extracted DNA was amplified using the primer sets shown in Table 1. Furthermore, Restriction Fragment Length Polymorphism (RFLA) was done to analyse TS5utr tandem repeat polymorphism.

The investigator (S Stintzing) reading the sequence was blinded to the clinical results. For quality control purposes, a random selection of $10 \%$ of the samples were resequenced for each SNP showing a concordance of $>99 \%$.

\section{Statistics}

In the statistical analysis of the NeoFLOT-trial, pCR was defined as pyT0N0. PFS was defined as the time elapsed between randomisation and progression or death, depending on what comes first. Patients not deceased without proven progression were included in the assessment as censored by the last date of free of progression. Likewise, OS was defined as time from randomization until death from 
Table 2 Baseline characteristics

\begin{tabular}{|c|c|}
\hline NeoFLOT subpopulation & Value $(\mathrm{N}=48)$ \\
\hline \multicolumn{2}{|l|}{ Gender } \\
\hline Male & $60 \%$ \\
\hline Female & $40 \%$ \\
\hline Age, median [range] (years) & $60.5[32-78]$ \\
\hline \multicolumn{2}{|l|}{ ECOG status } \\
\hline 0 & $69 \%$ \\
\hline 1 & $27 \%$ \\
\hline Unknown & $4 \%$ \\
\hline \multicolumn{2}{|l|}{ Clinical T stage } \\
\hline T2 & $18.8 \%$ \\
\hline T3 & $72.9 \%$ \\
\hline $\mathrm{T} 4$ & $6.3 \%$ \\
\hline Tx & $2.1 \%$ \\
\hline \multicolumn{2}{|l|}{ Clinical N stage } \\
\hline No & $16.7 \%$ \\
\hline N1 & $27.1 \%$ \\
\hline N2 & $18.8 \%$ \\
\hline N3 & $2.1 \%$ \\
\hline $\mathrm{N}+$ & $31.3 \%$ \\
\hline $\mathrm{Nx}$ & $4.2 \%$ \\
\hline \multicolumn{2}{|l|}{ Lauren classification } \\
\hline Diffuse & $29.2 \%$ \\
\hline Intestinal & $60.4 \%$ \\
\hline Mixed type & $6.3 \%$ \\
\hline Cannot be determined & $4.2 \%$ \\
\hline \multicolumn{2}{|l|}{ Grading } \\
\hline G2 & $43.8 \%$ \\
\hline G3 & $56.3 \%$ \\
\hline \multicolumn{2}{|l|}{ Tumor localization } \\
\hline GE-Junction & $56.2 \%$ \\
\hline Type I & $22.9 \%$ \\
\hline Type II & $22.9 \%$ \\
\hline Type III & $10.4 \%$ \\
\hline Antrum & $25.0 \%$ \\
\hline Corpus & $18.8 \%$ \\
\hline
\end{tabular}

Table 2 (continued)
Table 2 (continued)

\begin{tabular}{lc}
\hline NeoFLOT subpopulation & Value (N=48) \\
\hline Overall response rate (ORR) & $47.7 \%$ \\
Complete histological response (pCR) & $20.8 \%$ \\
Median PFS (95\% Cl) (months) & $22.1(8.0-36.3)$ \\
Median RFS (95\% Cl) (months) & NA \\
Median OS (95\% Cl) (months) & 39.1 (28.2-50.1) \\
\hline ECOG, Eastern Cooperative Oncology Group; GE, & $\begin{array}{l}\text { gastroesophageal; N, lymph node involvement according to TMN } \\
\text { classification; ORR, overall response rate; OS, overall survival; } \\
\text { pCR, complete pathological response; PFS, progression-free }\end{array}$ \\
$\begin{array}{l}\text { survival; RFS, relapse-free survival; T, depth of tumor invasion } \\
\text { according to TMN classification; NA, not available. }\end{array}$
\end{tabular}

any cause. RFS was defined as the time elapsed between randomisation and local, regional or distant recurrence or death due to any cause.

Deviations from the Hardy-Weinberg equilibrium (HWE) were tested using $\chi^{2}$ test. The associations between the allelic distribution of the SNPs and their potential association with toxicity and response [pathologic response (pCR) and ORR)] were examined using $\chi^{2}$ or Fisher's exact test. The statistical analysis was intentionally conducted without adjusting for multiple testing. The following CTC $\mathrm{AE}$ terms were used: anemia, leukopenia, neutropenia, thrombocytopenia, neurotoxicity and diarrhea.

The true inheritance mode of the analysed polymorphisms is unknown, therefore a co-dominant, dominant or recessive model was assumed wherever appropriate. The associations of the SNPs and survival times (PFS, RFS and OS) were analysed using Kaplan-Meier curves and log-rank test.

All calculations were performed using SPSS Statistics ${ }^{\circledR}$ version 23 (IBM, Armonk, NY, USA). All tests were twosided at a significance level of 0.05 .

\section{Results}

In this analysis, a total of 48 patients were included. The baseline characteristics of the study population are summarized in Table 2. With a median age of 60.5 years, $60 \%$ of the patients were male. Predominant clinical Tand N-stage was cT3 and cN1. Prevailing histology was intestinal, about $50 \%$ were GEJ tumors. Details of the study populations are shown in the CONSORT diagram (Figure 1). Of 59 enrolled patients in the NeoFLOTtrial, 50 patients underwent surgery and were treated with 


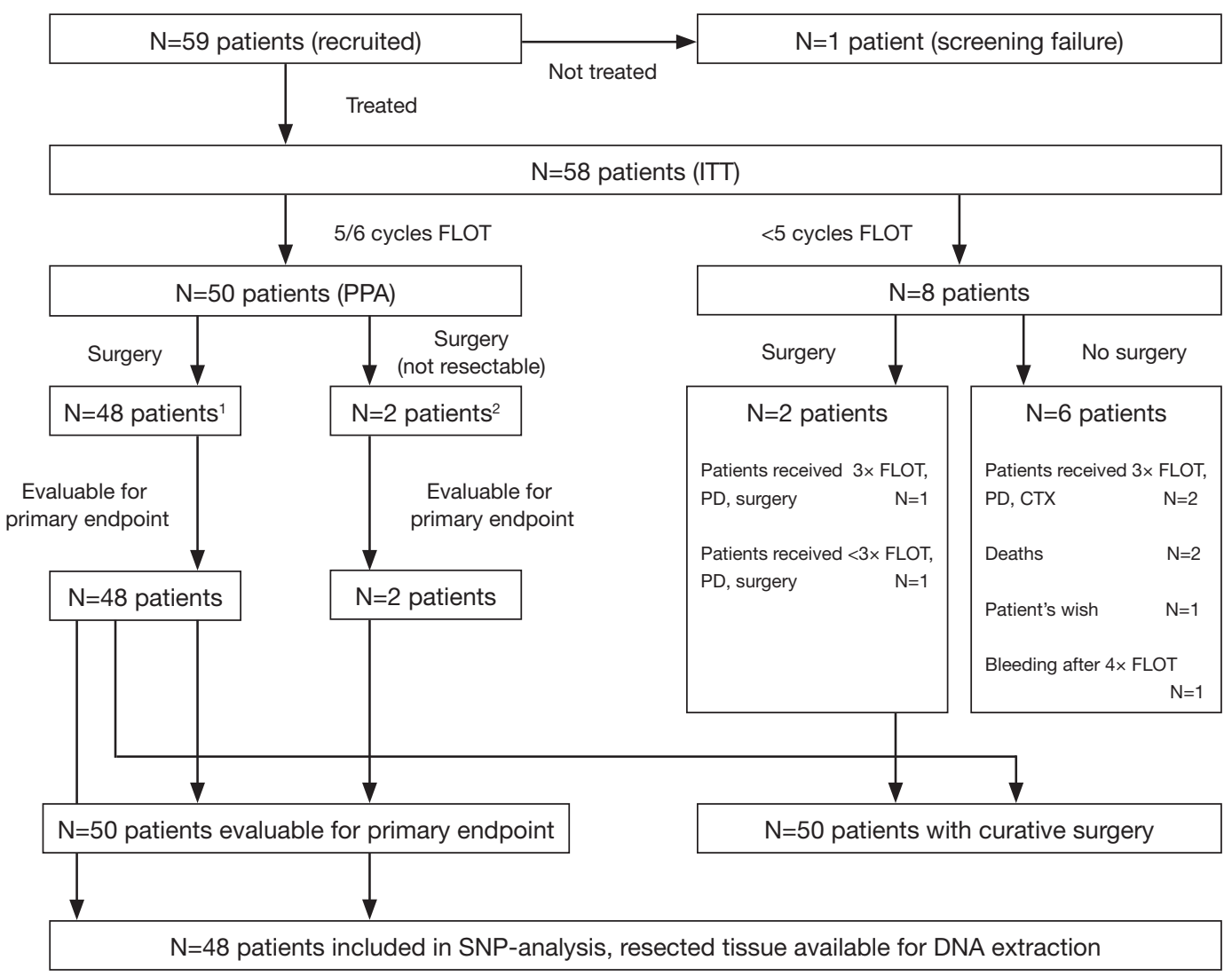

Figure 1 CONSORT diagram of the population tested within the NEOFLOT cohort. ', One patient had only 5 cycles FLOT (at patient's wish), 1 patient had $1 \times$ FLOT, $5 \times$ FLO due to an allergic reaction. ${ }^{2}$, One patient turned out to be inoperable due to tumor extension, 1 patient due to cirrhosis of the liver. CTX, chemotherapy; FLOT, 5-FU/oxaliplatin/docetaxel; ITT, intent-to-treat population; N, number; $\mathrm{PD}$, progressive disease; PPA, per protocol analysis.

mostly 6 cycles of FLOT. Two patients of the PP-cohort were inoperable due to tumor extension or liver cirrhosis. Therefore, resection specimen of 48 patients was available for DNA extraction and genotyping.

A total of 8 SNPs and one tandem repeat polymorphism have been associated with toxicity and efficacy of neoadjuvant FLOT chemotherapy. Genotyping of the SNPs could be carried out in at least $88 \%(42 / 48)$ of the cases. In failed cases, genotyping was not possible due to limited quantity and/or quality of the genomic DNA. The allelic frequencies for all SNPs were within the probability limits of HWE (P>0.05), except for OPRT rs1801019 which has been associated with gastric cancer before (Table S1) (18).

Data of the association of hematotoxicity with the respective SNP are shown in Tables 3-5. Non-significant results are presented in Tables S2-S4. Patients harbouring the A/A genotype of rs1799793 of ERCC2 significantly more often presented with thrombopenia $\geq$ grade
3 ( $\chi^{2}$ test $P=0.04$ ) compared to the $A / G$ and $G / G$ genotype. The major allele $\mathrm{G}$ of rs13181 of ERCC2 was significantly associated with less leukopenia $\geq$ grade 3 (Fisher's exact test $\mathrm{P}=0.03$ ) (Table 3).

The polymorphism of rs11615 of ERCC1 was associated with thrombocytopenia $\left(\chi^{2}\right.$ test $\left.\mathrm{P}=0.008\right)$ whereas the minor allele $\mathrm{C}$ was predictive for less toxicity. At the same time leukopenia occurred more often in patients with the T/T or T/C genotype compared to the $\mathrm{C} / \mathrm{C}$ genotype ( $\chi^{2}$ test $\mathrm{P}=0.02)($ Tables 4,5$)$.

The long 3R/3R TS5utr tandem repeat polymorphism was also found to be associated with anemia $\left(\chi^{2}\right.$ test $\left.\mathrm{P}=0.04\right)$.

For non-hematological toxicity, patients carrying the homozygous AA of the major allele A of rs1805087 had a highly significant risk of diarrhea (Fisher's exact test $\mathrm{P}=0.004$ ) (Table 6) and of diarrhea of higher grades $\left(\chi^{2}\right.$ test $\mathrm{P}=0.05$ ) (Table 7). With respect to gastrointestinal toxicity, the heterozygous genotype G/T of rs13181 significantly led 
Table 3 Association of hematological toxicity grade 0-2 vs. $\geq 3$ according to NCI-CTC (version 4) with SNPs of ERCC2

\begin{tabular}{|c|c|c|c|c|c|c|c|c|c|c|c|c|c|}
\hline SNP & $\mathrm{N}$ & \multicolumn{3}{|c|}{ Anemia grade, n (\%) } & \multicolumn{3}{|c|}{ Leukopenia grade, n (\%) } & \multicolumn{3}{|c|}{ Neutropenia grade, n (\%) } & \multicolumn{3}{|c|}{ Thrombocytopenia grade, $\mathrm{n}(\%)$} \\
\hline rs13181 & & & & 1.00 & & & 0.03 & & & 0.32 & & & 1.00 \\
\hline $\mathrm{G} / \mathrm{G}$ or $\mathrm{G} / \mathrm{T}$ & 32 & $31(96.9)$ & $1(3.1)$ & & $27(84.4)$ & $5(15.6)$ & & $24(75.0)$ & $8(25.0)$ & & $31(96.9)$ & $1(3.1)$ & \\
\hline $\mathrm{TT}$ & 15 & $15(100.0)$ & $0(0.0)$ & & $8(53.3)$ & $7(46.7)$ & & $9(60.0)$ & $6(40.0)$ & & $15(100.0)$ & $0(0.0)$ & \\
\hline AA & 6 & $6(100.0)$ & $0(0.0)$ & & $4(66.7)$ & $2(33.3)$ & & $6(100.0)$ & $0(0.0)$ & & 5 (83.3) & $1(16.7)$ & \\
\hline$A G$ & 20 & $19(95.0)$ & $1(5.0)$ & & $17(85.0)$ & $3(15.0)$ & & $15(75.0)$ & $5(25.0)$ & & $20(100.0)$ & $0(0.0)$ & \\
\hline GG & 19 & $19(100.0)$ & $0(0.0)$ & & $12(63.2)$ & $7(36.8)$ & & $10(52.6)$ & $9(47.4)$ & & $19(100.0)$ & $0(0.0)$ & \\
\hline
\end{tabular}

${ }^{*} \mathrm{P}$, chi-square-test or Fisher's exact test (two-sided) in case of $2 \times 2$ table. A, adenine; bp, base pair; C, cytosine; ERCC2, excision repair cross-complementation group 2; G, guanine; T, thymine; N, number; NCl-CTC, National Cancer Institute Common Toxicity Criteria; SNP, single nucleotide polymorphism.

Table 4 Association of maximal hematological toxicity (anemia, thrombocytopenia) according to NCI-CTC (version 4) with SNPs of TS, MTR, and ERCC1

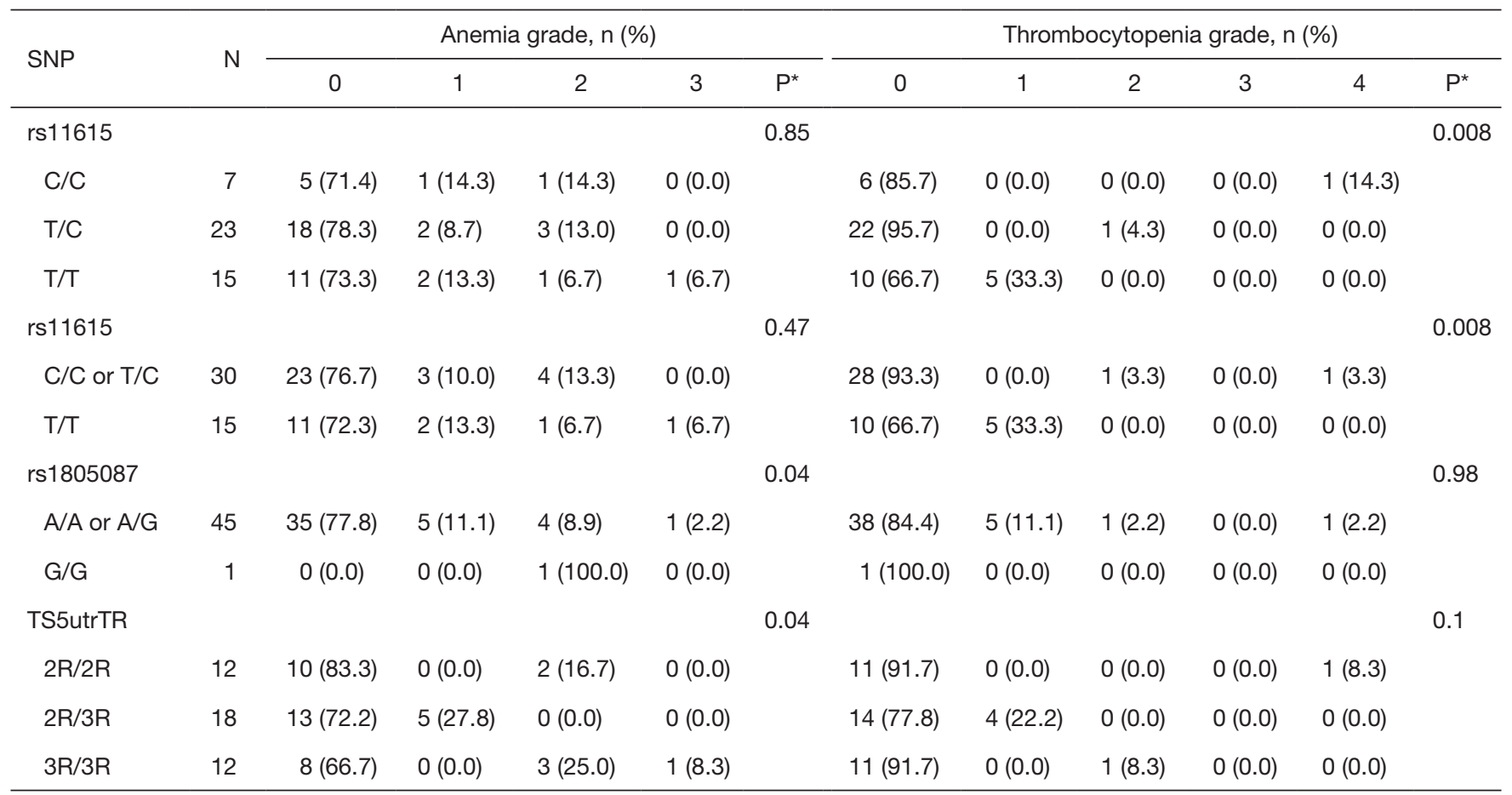

${ }^{*}$ P, chi-square test. A, adenine; bp, base pair; C, cytosine; ERCC1, Excision Repair Cross-Complementation Group 1; G, guanine; T, thymine; MTR, 5-methyltetrahydrofolate-homocysteine methyltransferase; N, number; NCl-CTC, National Cancer Institute Common Toxicity Criteria; SNP, single nucleotide polymorphism; TS5utr tandem repeat, thymidylate synthase: 28-bp-tandem repeats in the 5 untranslated region. 
Table 5 Association of maximal hematological toxicity (leukopenia, neutropenia) according to NCI-CTC (version 4) with SNPs of ERCC1

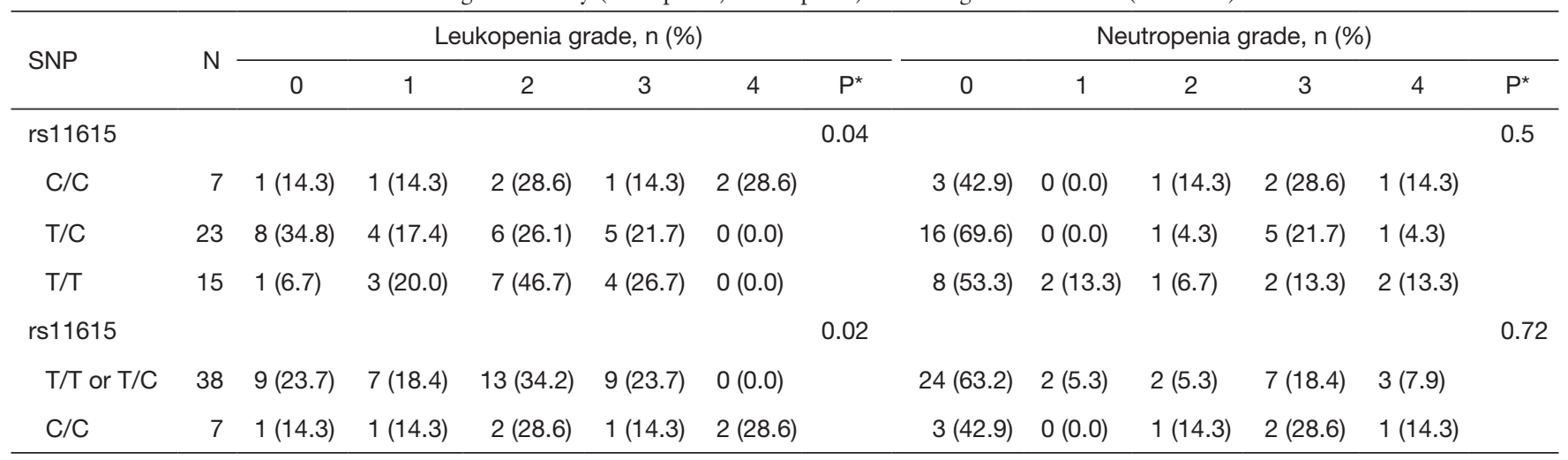

${ }^{*} \mathrm{P}$, chi-square test. A, adenine; bp, base pair; C, cytosine; ERCC1, Excision Repair Cross-Complementation Group 1; G, guanine; T, thymine; N, number; NCl-CTC, National Cancer Institute Common Toxicity Criteria; SNP, single nucleotide polymorphism.

Table 6 Association of non-hematological toxicity (diarrhea, neuropathy) $0-1 v s . \geq 2$ according to NCI-CTC (version 4) with SNPs of MTR

\begin{tabular}{|c|c|c|c|c|c|c|c|}
\hline SNP & $\mathrm{N}$ & \multicolumn{3}{|c|}{ Diarrhea grade, n (\%) } & \multicolumn{3}{|c|}{ Neuropathy grade, n (\%) } \\
\hline rs1805087 & & & & 0.02 & & & 0.73 \\
\hline$A / A$ & 34 & $19(55.9)$ & $15(44.1)$ & & $24(70.6)$ & $10(29.4)$ & \\
\hline$A / G$ & 11 & $11(100.0)$ & $0(0.0)$ & & $7(63.6)$ & $4(36.4)$ & \\
\hline rs1805087 & & & & 0.004 & & & 1.00 \\
\hline$A / A$ & 34 & $19(55.9)$ & $15(44.1)$ & & $24(70.6)$ & $10(29.4)$ & \\
\hline $\mathrm{A} / \mathrm{G}$ or $\mathrm{G} / \mathrm{G}$ & 12 & $12(100.0)$ & $0(0.0)$ & & $8(66.7)$ & $4(33.3)$ & \\
\hline
\end{tabular}

${ }^{*} \mathrm{P}$, chi-square test or Fisher's exact test (two-sided) in case of $2 \times 2$ tables. A, adenine; bp, base pair; C, cytosine; G, guanine; T, thymine; MTR, 5-methyltetrahydrofolate-homocysteine methyltransferase; N, number; NCI-CTC, National Cancer Institute Common Toxicity Criteria; SNP, single nucleotide polymorphism.

Table 7 Association of maximal non-hematological toxicity (diarrhea, neuropathy) according to NCI-CTC (version 4) with SNPs of MTR and ERCC2

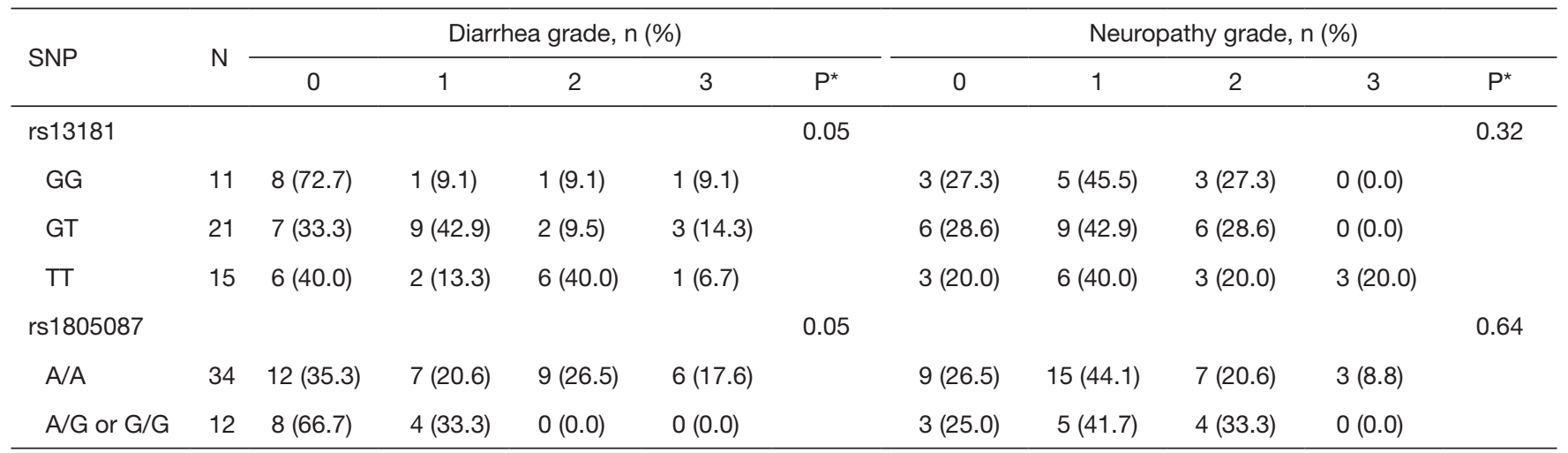

${ }^{*}$, chi-square test. A, adenine; bp, base pair; C, cytosine; ERCC2, Excision Repair Cross-Complementation Group 2; G, guanine; T, thymine; MTR, 5-methyltetrahydrofolate-homocysteine methyltransferase; N, number; NCl-CTC, National Cancer Institute Common Toxicity Criteria; SNP, single nucleotide polymorphism. 


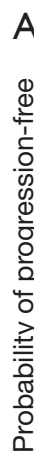

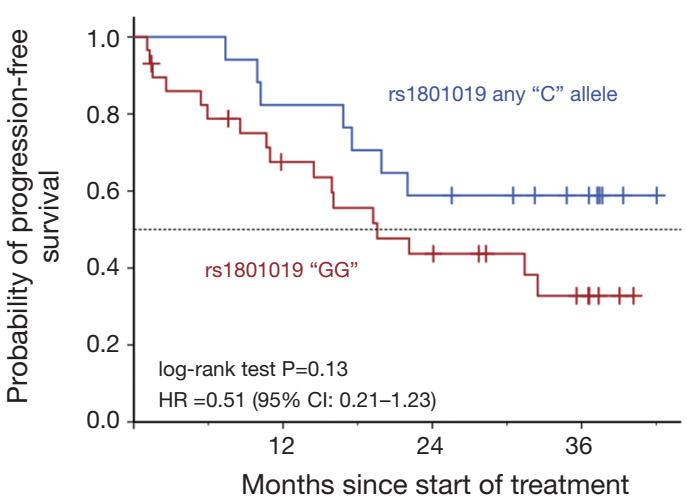

C

Progression-free survival

\begin{tabular}{lccc} 
& $\begin{array}{c}\text { rs1801019 } \\
\text { any "C" allele }\end{array}$ & $\begin{array}{c}\text { rs1801019 } \\
\text { "GG" }\end{array}$ & $\mathrm{P}^{*}$ \\
\hline $\begin{array}{l}\text { Overall response } \\
\text { rate (ORR) }\end{array}$ & $81 \%$ & $31 \%$ & 0.004 \\
\hline & & & \\
\hline
\end{tabular}

\section{B}

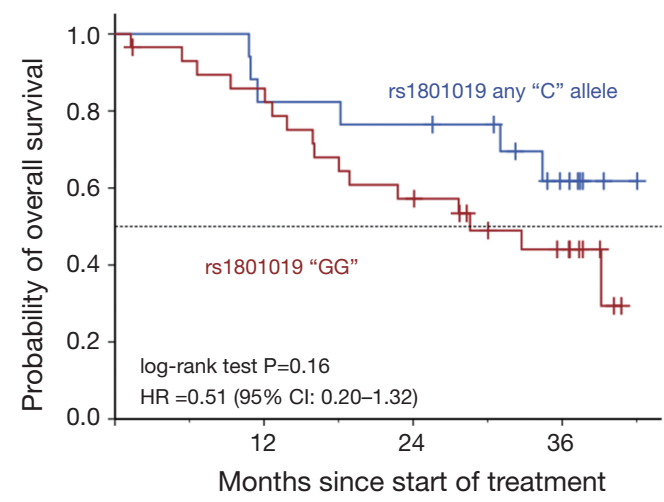

Figure 2 Kaplan-Meier estimates of progression-free survival (A) and overall survival (B) of the minor allele of Orotate phosphoribosyltransferase (OPRT) rs1801019. (C) Overall response rate of the minor allele of OPRT rs1801019. CI, confidence interval; HR, hazard ratio.

to more diarrhea compared to homogenous $\mathrm{G} / \mathrm{G}$ or $\mathrm{T} / \mathrm{T}$ genotype (Table 7). Non-significant results concerning nonhematological toxicity are available in Tables S5,S6.

The associations with efficacy according to pCR rate, ORR and survival are shown in the Supplement Tables $S 7, S 8$.

For rs1801019 of OPRT the minor allele C was associated with a significant higher ORR (81\% vs. 31\%, Fisher's exact test $\mathrm{P}=0.004$ ) and resulted in a longer PFS (log-rank test $\mathrm{P}=0.13, \mathrm{HR}=0.51)$, RFS $(\mathrm{P}=0.28 ; \mathrm{HR}=0.58)$ (data not shown), and OS $(\mathrm{P}=0.16 ; \mathrm{HR}=0.51)$ without reaching statistical significance (Figure 2).

Patients harbouring the minor allele T of rs3212986 of ERCC1 presented with higher pCR rate compared to the $\mathrm{G} / \mathrm{G}$ genotype (Fischer's exact test $\mathrm{P}=0.012$ ). A higher $\mathrm{pCR}$ rate could also be observed in patients with the rs3212986 G/T genotype of ERCC1 compared to G/G and T/T genotype ( $\chi^{2}$ test $\mathrm{P}=0.006$ ) (Table $S 7$ ). With respect to $\mathrm{PFS}$ and OS, this genotype did not show a significant association with survival (Table S8).

\section{Discussion}

In this study in patients with resectable GC and GEJ tumors receiving a prolonged neoadjuvant FLOT-chemotherapy, the impact of SNPs in genes of pyrimidine and methionine biosynthesis, DNA excision repair proteins, DNA repair cross-complementing protein and TS on toxicity and efficacy was analysed. Here we could demonstrate the influence of various polymorphisms, predominantly on hematotoxicity and to a lesser extent on non-haematological toxicity. The effect on treatment efficacy was less prominent and rather refers to response and $\mathrm{pCR}$ rate than to survival.

As gene expression analysis of gastric biopsy samples is afflicted with many technical problems hampering reliability, SNPs within the proximity of the genes of interest have the advantage of an easy measurement and high reproducibility. The existence of formalin-fixed paraffin embedded (FFPE) resection specimen ensures the access to tissue sufficient for genetic analysis with almost complete concordance between germline and somatic DNA in variants of pharmacogenetic genes (24).

Rather small sample size and the missing of a validation cohort apparently limit the current analyses. The analysis of the SNPs was carried out in the PP-population. Compared to the ITT-population, patients being treated with less than 5 cycles of FLOT due to PD, complications, patient's wish or death were excluded. Additionally, limited availability of resection specimen and subtotal successful genotyping lead to reduced quantity of analyses. With respect to limited case numbers, possible inaccuracies cannot be ruled out for the applied statistics. It has to be stipulated to retest the significant SNPs within a considerable larger cohort to enhance the clinical relevance. Furthermore, the statistical 
analysis of the present, exploratory analyses was carried out without correction for multiple testing.

While the role of ERCC1 and ERCC2 in DNA damage recognition and repair is undisputed, clinical data on outcome and toxicity under a platinum-based therapy are inconsistent. In the present trial in univariate analysis the A/A genotype of ERCC2 rs1799793 was significantly associated with the appearance of thrombocytopenia of higher grades. For this genotype the analysis by Goekkurt et al. displayed an association with leukopenia, neutropenia and nephrotoxicity $[\mathrm{P}=0.034 ; \mathrm{P}=0.32 ; \mathrm{P}=0.003$, respectively (univariate analysis)] and no effect on treatment efficacy (25). Our data showed an association of the minor allele $G$ with improved PFS and OS. This is in line with data from a trial with 360 GC patients, where the rs1799793 variant A/A was associated with significantly poorer $\mathrm{OS}(\mathrm{P}=0.012)$ and a significantly higher risk of death (AA vs. GG+AG, adjusted $\mathrm{HR}=2.13 ; \mathrm{P}=0.004)(26)$. A retrospective analysis with patients suffering from GC treated with EOF was also able to show that rs1799793 G/A genotype is associated with worse PFS ( $\mathrm{P}=0.034)$ and a trend to poorer OS $(\mathrm{P}=0.09)(27)$. Comparable are the results from two other GC trials showing that rs1799793 G/A and A/A genotype are associated with an improved response to chemotherapy $(\mathrm{OR}=1.61)$, a reduced risk of mortality $(\mathrm{HR}=1.97)(28)$ and a longer survival compared to the G/G genotype (HR $=0.57)$, respectively (29). Rs1799793 of ERCC2 has been tested by Zhou et al. and here the AA genotype had a significant association with survival in 415 patients treated with any platinum-based chemotherapy (16). Other Asian trials failed to show an association of the rs1799793 SNP with survival $(20,30,31)$.

Summarizing the conflicting data for rs1799793, the $\mathrm{G}$ allele might be associated with longer survival whereas patients bearing the A allele might have a shorter survival. Therefore, the impact on hematological toxicity is even more important as we are not able to change the prognosis associated with genetics but we could adapt the treatment by using lower oxaliplatin dosage in patients with the A allele of rs1799793.

In our analysis, ERCC2 polymorphism rs13181 homozygous $\mathrm{T} / \mathrm{T}$ genotype appeared to be associated with a higher rate of leukopenia grade 3 and above. Additionally, diarrhea occurred more often in patients carrying the $T$ allele. Furthermore, there was an association towards a higher pCR rate in genotypes bearing the $\mathrm{T}$ allele. This data is partly in line with previous reports where this SNP in metastatic GC patients was associated with leukopenia
$(\mathrm{P}=0.026)$ (25) with no impact on tumor response $(25,32)$. Xue et al. reported a significant association for ERCC2 rs13181 with response and survival in FOLFOX treated patients (20). Moreover, a meta-analysis of patients with GC and colorectal cancer treated with oxaliplatin described the $G$ allele of rs13181 to be associated with reduced objective response (33). The higher DNA repair capacity and the consecutive reduction of the anticancer effect of oxaliplatin caused by the $\mathrm{G}$ allele might be the underlying biological rationale for these clinical observations (33). The negative association of the G allele of rs13181 and outcome was confirmed by other authors who propose the combined analysis of rs13181 with others SNPs $(26,27)$ whereas some analyses failed to demonstrate this association $(9,31,34)$. Reasons for this may well be the inconsistency of the investigated chemotherapeutic regimen, differences in ethnicity and the limited number of cases investigated.

ERCC1 rs11615 TT genotype has been reported to convey poorer response and shorter survival in metastatic GC (35). In patients with metastatic GC and GEJ tumors, neutropenia of higher grades was associated with the ERCC1 118T/8092C haplotype (25). In the same trial the presence of the ERCC1-118C/8092C haplotype (wild-type) was significantly associated with response.

For ERCC1, the current data indicate the $\mathrm{T}$ allele of rs11615 to be associated with higher frequency of thrombocytopenia and leukopenia (Tables 4,5$)$ without any impact on treatment efficacy. Data from a meta-analysis of predominantly colorectal tumors of Asian patients treated with oxaliplatin conveyed an association of the $\mathrm{T}$ allele of rs11615 with reduced response, PFS, and OS (33). A similar finding was seen in a Chinese study of patients with GC treated with FOLFOX. The T allele of rs11615 was associated with poorer response rate and decreased OS compared with the CC genotype (30). Further data on rs11615 is confounding. While some authors were able to reproduce this data $(16,35)$, others fail to detect an association of rs11615 with prognosis $(31,36)$. In prior trials by Goekkurt et al. of patients with mainly metastatic GC and GEJ tumors being treated with FLOT or cisplatin with 5-FU, genotyping revealed no impact of ERCC1 rs11615 on toxicity or efficacy $(9,10)$.

In the current analysis, the rs3212986 of ERCC1 was significantly associated with $\mathrm{pCR}$ rate with patients carrying the G/G genotype having the lowest histopathological response. Rs3212986 has also been identified to be predictive for response and OS in a mixed cohort of UICC I to UICC IV GC patients treated with FOLFOX (20). While in 
previous trials in GC and esophageal cancer this SNP was associated with response to therapy (37-39), others failed to show an association with response $(29,32,40)$. In line with our data, no impact on hematotoxicity was described (10). So again, the data on rs3212986 is not univocal.

For rs1805087 of MTR, the presence of the G/G genotype is statistically significant associated with anemia of higher grades and a trend to neutropenia, which due to the small sample size leading to inaccuracy cannot be transferred in the clinical context. In the palliative setting, the finding by Goekkurt et al. revealed a significant association with neutropenia (25). Moreover, rs1805087 has been reported to be of predictive value after radiochemotherapy for squamous cell esophageal cancer (41) and has been associated with hematotoxicity in 5-FU- and platinum-treated patients suffering from advanced GC (25).

The TS repeat polymorphism has been extensively investigated. Another SNP in the 3'-untranslated region (3'-UTR) of the TS gene (rs16430; 1490del6) had influence on clinical outcome in 5-FU-treated patients with colorectal cancer presumably by a lower intratumoral TS mRNA levels $(22,42)$. Goekkurt et al. reported a trend for more hematotoxicity of higher grades for the $2 \mathrm{R} / 2 \mathrm{R}$ or $2 \mathrm{R} / 3 \mathrm{R}$ genotype compared to the $3 \mathrm{R} / 3 \mathrm{R}$ genotype and non-significant higher rates of neutropenia grade 3 and 4 (2R/2R: $66.7 \%$; 2R/3R: 38.5\%, 3R/3R: $25 \%$; $\mathrm{P}=0.10$, chisquare test) (10). Here, our data also reveal a higher grade of hematotoxicity with higher rates of anemia.

For rs1801019 (OPRT-Gly213Ala) we found a significant association of the minor $\mathrm{C}$ allele with tumor response that translated into a longer but statistically non-significant enhanced PFS and OS. This finding is partially supported by the data of Goekkurt et al. with a statistically significant association of Ala/ Ala with shorter OS and a trend towards shorter PFS (25).

Although multiple publications have characterized SNPs to predict efficacy and outcome in patients with gastrointestinal malignancies, all authors, including those of the current publication, used different chemotherapeutic regimen and/or settings, which makes it difficult to compare the findings. Still, we do see certain transferability, especially when it comes to toxicity.

Nevertheless, using samples from a prospective study with a well-defined and monitored dataset enables us to generate hypotheses which eventually have to be validated in an independent study population using the same chemotherapeutic approach and setting. This aspect is gaining particular importance with regard of the forthcoming use of the FLOT regimen considering the latest perioperative efficacy and toxicity results $(6,7)$.

\section{Conclusions}

Germline polymorphism of ERCC1 (rs11615), ERCC2 (rs13181 and rs1799793), MTR (rs1805087) and TS promotor polymorphism might be associated with toxicity in patients suffering from GC and GEJ tumors treated with FLOT as neoadjuvant regimen. An association with clinical and histopathological response was seen for ORPT (rs1801019) and ERCC1 (rs3212986). To our knowledge, this is the first report on the impact of SNPs on toxicity and treatment efficacy during an intensified preoperative treatment with FLOT. Future validation in comparable cohorts and with larger patient numbers is necessarily required. Together with our findings, these results will help to design prospective validation studies to define SNPs for toxicity and efficacy prediction in neoadjuvant treatment with FLOT in operable GC and GEJ adenocarcinoma.

\section{Acknowledgments}

Funding: The authors thank all patients and their families who have participated in the trial. Furthermore, authors thank all centres for patient recruitment. C Schulz was supported by a grant of the 'Dr. Sepp und Hanne SturmGedächtnisstiftung', Munich, Germany.

\section{Footnote}

Conflicts of Interest: V Heinemann has received funding for scientific projects, honoraria for advisory boards and talks from Sanofi-Aventis. S Stintzing has received honoraria and travel support from Sanofi-Aventis. The other authors have no conflicts of interest to declare.

Ethical Statement: The authors are accountable for all aspects of the work in ensuring that questions related to the accuracy or integrity of any part of the work are appropriately investigated and resolved. The study was conducted in accordance with the Declaration of Helsinki (as revised in 2013). All patients had given their written informed consent for the trial and the translational research (ethic committee of the LMU \#252-09).

Open Access Statement: This is an Open Access article distributed in accordance with the Creative Commons Attribution-NonCommercial-NoDerivs 4.0 International 
License (CC BY-NC-ND 4.0), which permits the noncommercial replication and distribution of the article with the strict proviso that no changes or edits are made and the original work is properly cited (including links to both the formal publication through the relevant DOI and the license). See: https://creativecommons.org/licenses/by-nc-nd/4.0/.

\section{References}

1. Starling N, Cunningham D. The role of systemic therapy for localised gastric cancer. Ann Oncol 2006;17 Suppl 10:x115-21.

2. Siewert JR, Bottcher K, Stein HJ, et al. Relevant prognostic factors in gastric cancer: ten-year results of the German Gastric Cancer Study. Ann Surg 1998;228:449-61.

3. Kulig P, Sierzega M, Pach R, et al. Differences in prognosis of Siewert II and III oesophagogastric junction cancers are determined by the baseline tumour staging but not its anatomical location. Eur J Surg Oncol 2016;42:1215-21.

4. Ge L, Wang HJ, Yin D, et al. Effectiveness of 5 -flurouracil-based neoadjuvant chemotherapy in locallyadvanced gastric/gastroesophageal cancer: a meta-analysis. World J Gastroenterol 2012;18:7384-93.

5. Cunningham D, Allum WH, Stenning SP, et al. Perioperative chemotherapy versus surgery alone for resectable gastroesophageal cancer. N Engl J Med 2006;355:11-20.

6. Al-Batran SE, Hofheinz RD, Pauligk C, et al. Histopathological regression after neoadjuvant docetaxel, oxaliplatin, fluorouracil, and leucovorin versus epirubicin, cisplatin, and fluorouracil or capecitabine in patients with resectable gastric or gastro-oesophageal junction adenocarcinoma (FLOT4-AIO): results from the phase 2 part of a multicentre, open-label, randomised phase $2 / 3$ trial. Lancet Oncol 2016;17:1697-708.

7. Al-Batran SE, Homann N, Schmalenberg H, et al. Perioperative chemotherapy with docetaxel, oxaliplatin, and fluorouracil/leucovorin (FLOT) versus epirubicin, cisplatin, and fluorouracil or capecitabine (ECF/ECX) for resectable gastric or gastroesophageal junction (GEJ) adenocarcinoma (FLOT4-AIO): A multicenter, randomized phase 3 trial. J Clin Oncol 2017;35:4004.

8. Schulz C, Kullmann F, Kunzmann V, et al. NeoFLOT: Multicenter phase II study of perioperative chemotherapy in resectable adenocarcinoma of the gastroesophageal junction or gastric adenocarcinoma-Very good response predominantly in patients with intestinal type tumors. Int J Cancer 2015;137:678-85.

9. Goekkurt E, Hoehn S, Wolschke C, et al. Polymorphisms of glutathione S-transferases (GST) and thymidylate synthase (TS)--novel predictors for response and survival in gastric cancer patients. Br J Cancer 2006;94:281-6.

10. Goekkurt E, Al-Batran SE, Mogck U, et al. Pharmacogenetic analyses of hematotoxicity in advanced gastric cancer patients receiving biweekly fluorouracil, leucovorin, oxaliplatin and docetaxel (FLOT): a translational study of the Arbeitsgemeinschaft Internistische Onkologie (AIO). Ann Oncol 2009;20:481-5.

11. Li Z, Xing X, Shan F, et al. ABCC2-24C > T polymorphism is associated with the response to platinum/5-Fu-based neoadjuvant chemotherapy and better clinical outcomes in advanced gastric cancer patients. Oncotarget 2016;7:55449-57.

12. Lu JW, Gao CM, Wu JZ, et al. Polymorphism in the 3 '-untranslated region of the thymidylate synthase gene and sensitivity of stomach cancer to fluoropyrimidinebased chemotherapy. J Hum Genet 2006;51:155-60.

13. Mandola MV, Stoehlmacher J, Muller-Weeks S, et al. A novel single nucleotide polymorphism within the $5^{\prime}$ tandem repeat polymorphism of the thymidylate synthase gene abolishes USF-1 binding and alters transcriptional activity. Cancer Res 2003;63:2898-904.

14. Fareed KR, Kaye P, Soomro IN, et al. Biomarkers of response to therapy in oesophago-gastric cancer. Gut 2009;58:127-43.

15. Zhao T, Xu Z, Gu D, et al. The effects of genomic polymorphisms in one-carbon metabolism pathways on survival of gastric cancer patients received fluorouracilbased adjuvant therapy. Sci Rep 2016;6:28019.

16. Zhou J, Liu ZY, Li CB, et al. Genetic polymorphisms of DNA repair pathways influence the response to chemotherapy and overall survival of gastric cancer. Tumour Biol 2015;36:3017-23.

17. Xu J, Ma J, Zong HT, et al. Pharmacogenetic role of XRCC1 polymorphisms on the clinical outcome of gastric cancer patients with platinum-based chemotherapy: a systematic review and meta-analysis. Genet Mol Res 2014;13:1438-46.

18. Lee JH, Kim Y, Choi JW, et al. Genetic variants and risk of gastric cancer: a pathway analysis of a genome-wide association study. Springerplus 2015;4:215.

19. Cheng C, Lingyan W, Yi H, et al. Association between TLR2, MTR, MTRR, XPC, TP73, TP53 genetic polymorphisms and gastric cancer: a meta-analysis. Clin Res Hepatol Gastroenterol 2014;38:346-59.

20. Xue MH, Li GY, Wu XJ, et al. Genetic variability of genes in NER pathway influences the treatment outcome of 
gastric cancer. Int J Clin Exp Pathol 2015;8:5563-9.

21. Wu H, Xu C, Chen G, et al. X-ray repair crosscomplementing 1 polymorphism and prognosis of platinumbased chemotherapy in gastric and colorectal cancer: a meta-analysis. J Gastroenterol Hepatol 2014;29:926-33.

22. Stoehlmacher J, Park DJ, Zhang W, et al. A multivariate analysis of genomic polymorphisms: prediction of clinical outcome to 5-FU/oxaliplatin combination chemotherapy in refractory colorectal cancer. Br J Cancer 2004;91:344-54.

23. Ulrich CM, Bigler J, Velicer CM, et al. Searching expressed sequence tag databases: discovery and confirmation of a common polymorphism in the thymidylate synthase gene. Cancer Epidemiol Biomarkers Prev 2000;9:1381-5.

24. McWhinney SR, McLeod HL. Using germline genotype in cancer pharmacogenetic studies. Pharmacogenomics 2009;10:489-93.

25. Goekkurt E, Al-Batran SE, Hartmann JT, et al. Pharmacogenetic analyses of a phase III trial in metastatic gastroesophageal adenocarcinoma with fluorouracil and leucovorin plus either oxaliplatin or cisplatin: a study of the arbeitsgemeinschaft internistische onkologie. J Clin Oncol 2009;27:2863-73.

26. Li Y, Liu Z, Liu H, et al. ERCC1 and ERCC2 variants predict survival in gastric cancer patients. PLoS One 2013;8:e71994.

27. Liu R, Zhao X, Liu X, et al. Influences of ERCC1, ERCC2, XRCC1, GSTP1, GSTT1, and MTHFR polymorphisms on clinical outcomes in gastric cancer patients treated with EOF chemotherapy. Tumour Biol 2016;37:1753-62.

28. Ding C, Zhang H, Chen K, et al. Genetic variability of DNA repair mechanisms influences treatment outcome of gastric cancer. Oncol Lett 2015;10:1997-2002.

29. Yu WH, Wang YX, Guo JQ, et al. Genetic variability of ERCC1 and ERCC2 influences treatment outcomes in gastric cancer. Genet Mol Res 2015;14:17529-35.

30. Zhong G, Li HK, Shan T, et al. Genetic variability of DNA repair mechanisms in chemotherapy treatment outcome of gastric cancer patients. Genet Mol Res 2015;14:17228-34.

31. Mo J, Luo M, Cui J, et al. Prognostic value of ERCC1 and ERCC2 gene polymorphisms in patients with gastric cancer receiving platinum-based chemotherapy. Int J Clin Exp Pathol 2015;8:15065-71.

32. Yu H, Wu X, Zhang Y, et al. Genetic variability of DNA repair mechanisms influences chemotherapy outcome of gastric cancer. Int J Clin Exp Pathol 2015;8:4106-12.

33. Yin M, Yan J, Martinez-Balibrea E, et al. ERCC1 and
ERCC2 polymorphisms predict clinical outcomes of oxaliplatin-based chemotherapies in gastric and colorectal cancer: a systemic review and meta-analysis. Clin Cancer Res 2011;17:1632-40.

34. Zheng DL, Tang GD, Chen YN, et al. Genetic variability of ERCC1 and ERCC2 genes involved in the nucleotide excision repair pathway influences the treatment outcome of gastric cancer. Genet Mol Res 2016;15:gmr7384.

35. Liu L, Li CH, Jin TF, et al. Study on the ERCC1 gene polymorphism response to chemotherapy and prognosis of gastric cancer. Genet Mol Res 2014;13:8722-8.

36. Chen ZH, Wang L, Luo LP. Association of DNA repair gene polymorphisms with response to chemotherapy and prognosis of gastric cancer. Genet Mol Res 2014;13:7484-91.

37. Park SR, Kong SY, Nam BH, et al. CYP2A6 and ERCC1 polymorphisms correlate with efficacy of S-1 plus cisplatin in metastatic gastric cancer patients. Br J Cancer 2011;104:1126-34.

38. Bradbury PA, Kulke MH, Heist RS, et al. Cisplatin pharmacogenetics, DNA repair polymorphisms, and esophageal cancer outcomes. Pharmacogenet Genomics 2009;19:613-25.

39. Rumiato E, Boldrin E, Malacrida S, et al. A germline predictive signature of response to platinum chemotherapy in esophageal cancer. Transl Res 2016;171:29-37.e1.

40. Warnecke-Eberz U, Vallbohmer D, Alakus H, et al. ERCC1 and XRCC1 gene polymorphisms predict response to neoadjuvant radiochemotherapy in esophageal cancer. J Gastrointest Surg 2009;13:1411-21.

41. Sarbia M, Stahl M, von Weyhern C, et al. The prognostic significance of genetic polymorphisms (Methylenetetrahydrofolate Reductase C677T, Methionine Synthase A2756G, Thymidilate Synthase tandem repeat polymorphism) in multimodally treated oesophageal squamous cell carcinoma. Br J Cancer 2006;94:203-7.

42. Dotor E, Cuatrecases M, Martinez-Iniesta M, et al. Tumor thymidylate synthase 1494del6 genotype as a prognostic factor in colorectal cancer patients receiving fluorouracilbased adjuvant treatment. J Clin Oncol 2006;24:1603-11.

Cite this article as: Schulz C, Zhang W, Lenz HJ, Neumann J, Kullmann F, Kunzmann V, Fuchs M, Heinemann V, Holch JW, Stintzing S. Germline polymorphisms (SNPs) to predict toxicity and efficacy in FLOT-treated patients with locally advanced gastroesophageal junction or gastric adenocarcinoma-data from the NeoFLOT study. Transl Cancer Res 2018;7(6):13931405. doi: 10.21037/tcr.2018.11.03 


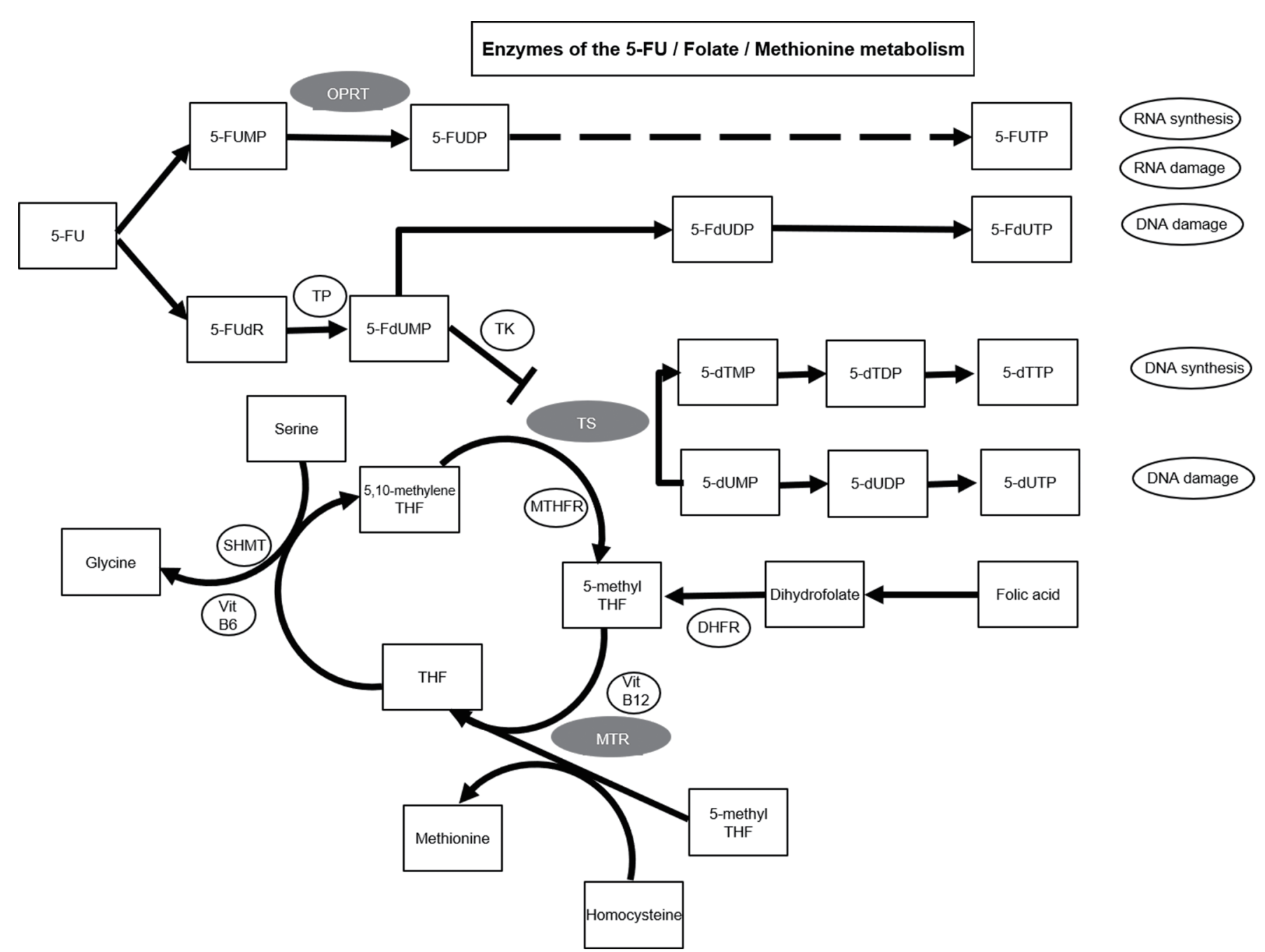

Figure S1 The metabolism of 5-FU and methionine and their pathways. The genes tested within this analysis are highlighted in grey. DHFR, dihydrofolate reductase; MTR, Methionine Synthase; MTHFR, Methylenetetrahydrofolate reductase; OPRT, orotate phosphoribosyltransferase; SHMT, Serine hydroxylmethyltransferase; THF, tetrahydrofolate; TP, thymidine phosphorylase; TS, thymidylate synthase; TK, thymidine kinase; 5-dTMP, 5-deoxythymidine monophosphate; 5-FU, 5-Fluorouracil; 5-dUMP, deoxy-uridine monophosphate; 5-FdUDP, 5-fluoro-deoxyuridinediphosphate; 5-FdUMP, 5-fluorodeoxyuridine monophosphate; 5 methyl THF, 5 methyl tetrahydrofolate; 5-FUDP, 5-fluorouridine diphosphate; 5-FUdR, 5-fluorodeoxyuridine; 5-FUMP, 5-fluorouridine monophosphate; 5-FUTP, 5-fluorouridine triphosphate; 5,10 methylene THF, 5,10-methylene-tetrahydrofolate. Adapted with permission by BMJ Publishing Group Limited (14) and by permission from Springer Nature Customer Service Centre GmbH: Springer Nature (41).

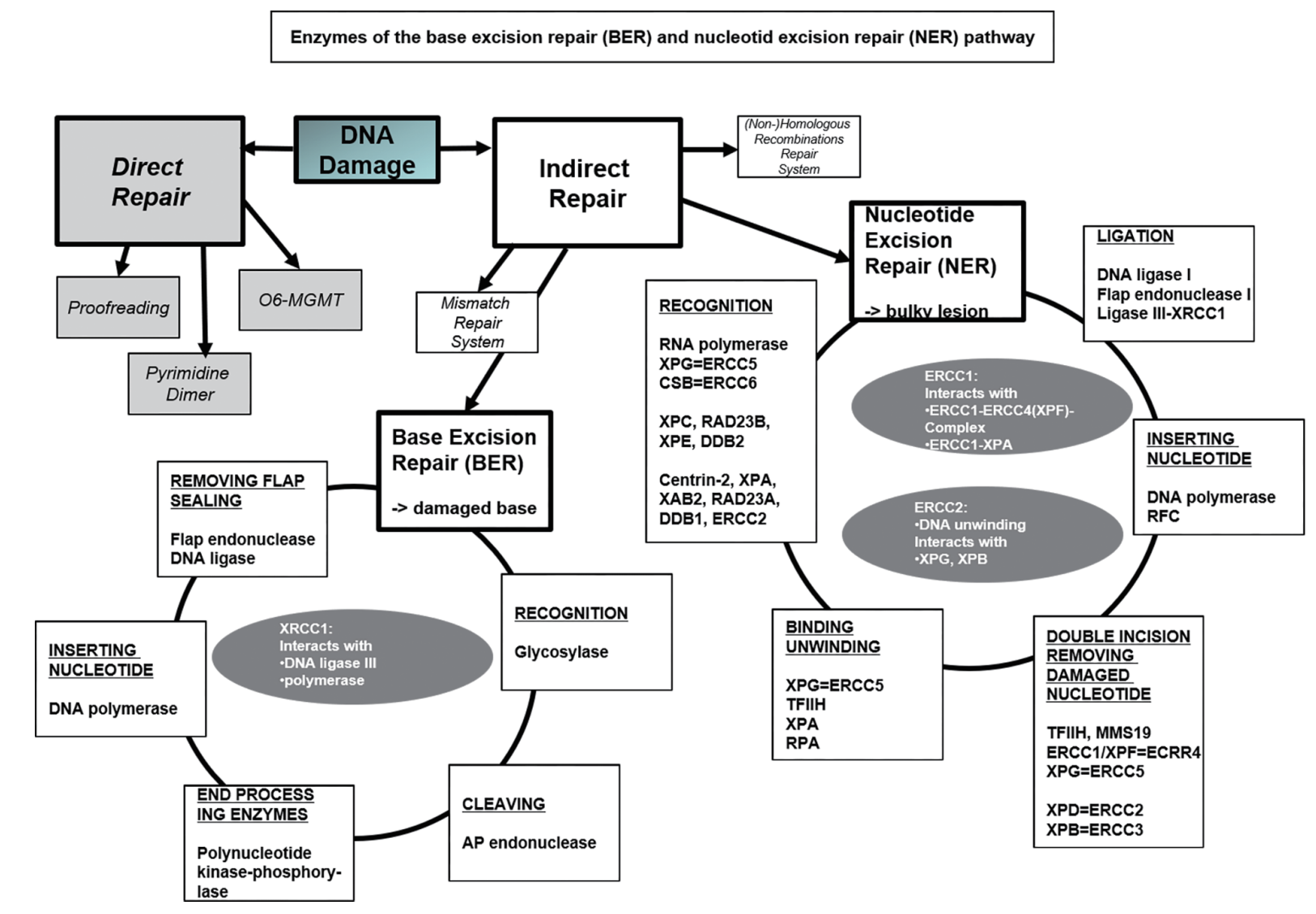

Figure S2 The base excision repair (BER) and the nucleotid excision repair (NER) pathways. The genes tested within this analysis are highlighted in grey. AP endonuclease, apurinic/apyrimidinic endonuclease; BER, base excision repair; CSB CS-B protein, also ERCC6; DNA, deoxyribonucleic acid; DDB1, DNA damage-binding protein 1; DDB2, damage specific DNA binding protein 2; NER, nucleotide excision repair; O6-MGMT, O6-methylguanin-DNAmethyltransferase; ERCC1, excision repair cross-complementation group 1; ERCC2, excision repair cross-complementation group 2; ERCC5, excision repair cross-complementation group 5; ERCC6, excision repair cross-complementation group 6; MMS19, MMS19 nucleotide excision repair protein homolog; RAD23A, UV excision repair protein RAD23; RFC, replication factor C; RNA, ribonucleic acid; RPA, replication protein A; TFIIH, transcription factor II human; XAB2, XPA binding protein 2; XPA, Xeroderma Pigmentosum complementation group A; XPB, Xeroderma Pigmentosum complementation group B, also ERCC3; XPC, Xeroderma Pigmentosum complementation group C; XPD, Xeroderma Pigmentosum complementation group D, also ERCC2; XPF, Xeroderma Pigmentosum complementation group F, also ERCC4; XPG, Xeroderma Pigmentosum complementation group G, also ERCC5; XRCC1, X-ray repair cross-complementing protein 1

Table S1 Chi-square to test the Hardy-Weinberg equilibrium hypothesis of the SNPs

\begin{tabular}{|c|c|c|c|c|c|c|c|c|c|}
\hline \multirow[b]{2}{*}{ Gene SNP } & \multicolumn{3}{|c|}{ Observed' } & \multicolumn{3}{|c|}{ Expected $^{1}$} & \multirow{2}{*}{$\begin{array}{l}\text { Variant allele } \\
\text { frequency }\end{array}$} & \multirow[b]{2}{*}{$x^{2}$} & \multirow{2}{*}{$\begin{array}{l}\chi^{2} \text { test } P \\
\text { value }\end{array}$} \\
\hline & $\begin{array}{l}\text { Homozygote } \\
\text { reference }\end{array}$ & Heterozygote & $\begin{array}{c}\text { Homozygote } \\
\text { variant }\end{array}$ & $\begin{array}{l}\text { Homozygote } \\
\text { reference }\end{array}$ & Heterozygote & $\begin{array}{c}\text { Homozygote } \\
\text { variant }\end{array}$ & & & \\
\hline OPRT rs1801019 & 25 & 9 & 8 & 20.7 & 17.6 & 3.7 & 0.30 & 9.98 & 0.001 \\
\hline MTR rs 1805087 & 34 & 11 & 1 & 33.9 & 11.2 & 0.9 & 0.14 & 0.01 & 0.92 \\
\hline ERCC1 rs11615 & 15 & 23 & 7 & 15.6 & 21.8 & 7.6 & 0.41 & 0.14 & 0.71 \\
\hline ERCC1 rs3212986 & 26 & 17 & 3 & 25.9 & 17.3 & 2.9 & 0.25 & 0.01 & 0.92 \\
\hline ERCC2 rs 13181 & 15 & 21 & 11 & 13.8 & 23.3 & 9.8 & 0.46 & 0.47 & 0.49 \\
\hline ERCC2 rs1799793 & 21 & 19 & 6 & 20.2 & 20.6 & 5.2 & 0.34 & 0.26 & 0.61 \\
\hline XRCC1 rs25487 & 19 & 16 & 11 & 15.8 & 22.3 & 7.8 & 0.41 & 3.68 & 0.06 \\
\hline TS3utrdel rs16430del & 21 & 17 & 10 & 18.1 & 22.7 & 7.1 & 0.39 & 3.06 & 0.08 \\
\hline $\begin{array}{l}\text { TS5utr tandem repeat } \\
\text { 28-bp Tandem }\end{array}$ & 12 & 19 & 11 & 11.0 & 21.0 & 10.0 & 0.49 & 0.38 & 0.54 \\
\hline
\end{tabular}

${ }_{1}$, not accurate if $<5$ individuals in any genotype group: ${ }^{2}$ P. chi-square test. ${ }^{3}$, if $\mathrm{P}$ value $<0.05$ not consistent with Hardy-Weinberg equilibrium. ERCC1, excision , not accurate if <5 indvidus repair cross-complementalion grou 1 , ERCC2, exision repair cross-complem regulatory region; TS5utr tandem repeat, thymidylate synthase: 28-bp-tandem repeats in the 5' untranslated region; XRCC1, X-Ray Repair Complementing Defective Repair in Chinese Hamster Cells 1. 
Table S2 Association of hematological toxicity grade 0-2 vs. $\geq 3$ according to NCI-CTC (version 4) with SNPs of TS, XRCC1, UMPS (OPRT), MTR, ERCC1 and ERCC2

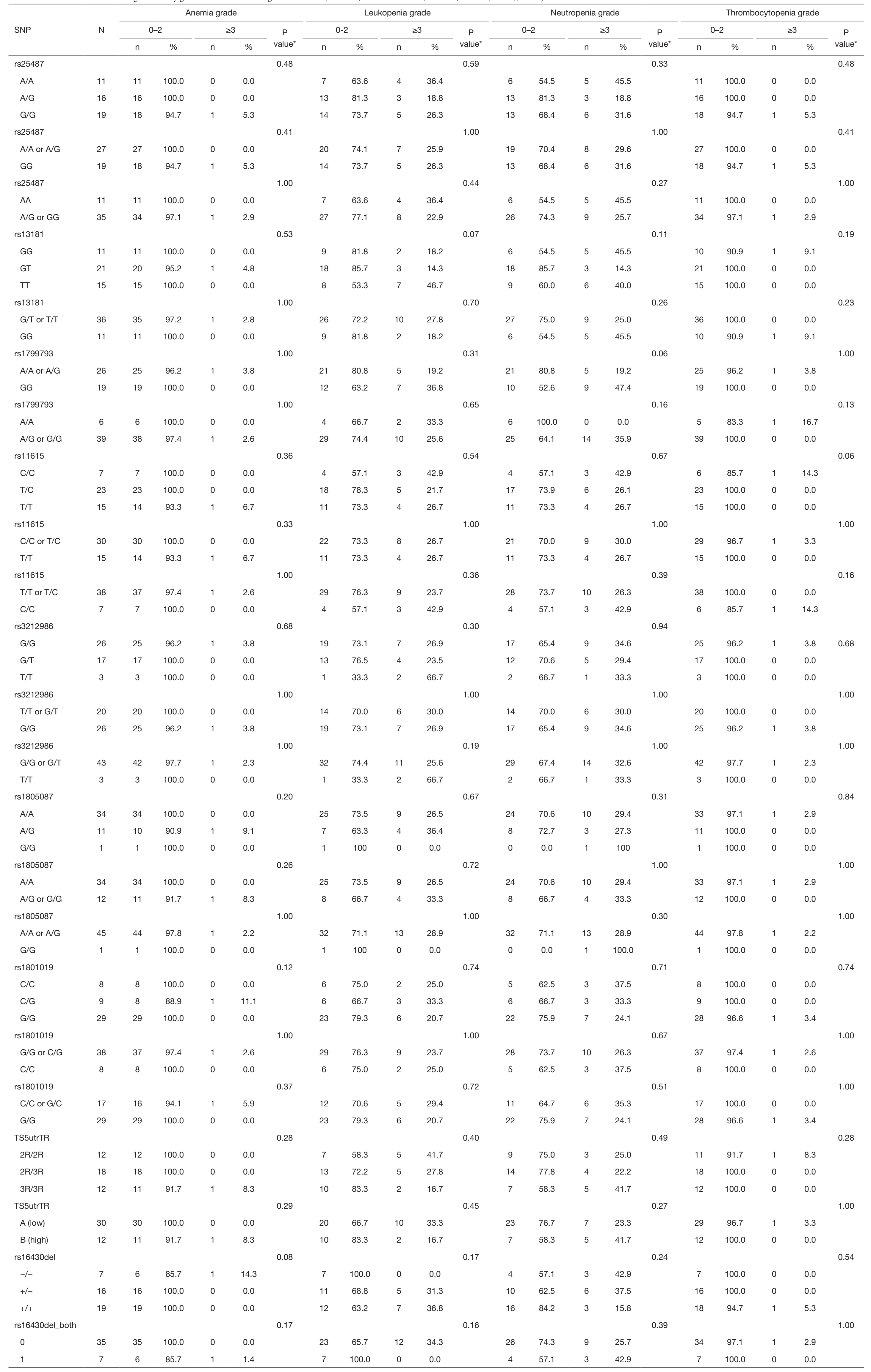


Table S3 Association of maximal hematological toxicity (anemia, thrombocytopenia) according to NCI-CTC (version 4) with SNPs of TS, XRCC1, UMPS (OPRT), MTR, ERCC1 and ERCC2

\begin{tabular}{|c|c|c|c|c|c|c|c|c|c|c|c|c|c|c|c|c|c|c|c|c|c|}
\hline \multirow{3}{*}{ SNP } & \multirow{3}{*}{$\mathrm{N}$} & & & & & emia & & & & & & & & & & Docytc & gra & & & & \\
\hline & & & & & & & & & & Pvalue ${ }^{*}$ & & & & & & & & & & & Pvalue \\
\hline & & $n$ & $\%$ & $n$ & $\%$ & $\mathrm{n}$ & $\%$ & $n$ & $\%$ & $n$ & $n$ & $\%$ & $n$ & $\%$ & $\mathrm{n}$ & $\%$ & $n$ & $\%$ & $n$ & $\%$ & \\
\hline rs25487 & & & & & & & & & & 0.56 & & & & & & & & & & & 0.24 \\
\hline A/A & 11 & 9 & 81.8 & 2 & 18.2 & 0 & 0.0 & 0 & 0.0 & & 8 & 72.7 & 3 & 27.3 & 0 & 0.0 & 0 & 0.0 & 0 & 0.0 & \\
\hline$A / G$ & 16 & 11 & 68.8 & 2 & 12.5 & 3 & 18.8 & 0 & 0.0 & & 14 & 87.5 & 2 & 12.5 & 0 & 0.0 & 0 & 0.0 & 0 & 0.0 & \\
\hline $\mathrm{G} / \mathrm{G}$ & 19 & 15 & 78.9 & 1 & 5.3 & 2 & 10.5 & 1 & 5.3 & & 17 & 89.5 & 0 & 0.0 & 1 & 5.3 & 0 & 0.0 & 1 & 5.3 & \\
\hline rs25487 & & & & & & & & & & 0.49 & & & & & & & & & & & 0.09 \\
\hline $\mathrm{A} / \mathrm{A}$ or $\mathrm{A} / \mathrm{G}$ & 27 & 20 & 74.1 & 4 & 14.8 & 3 & 11.1 & 0 & 0.0 & & 22 & 81.5 & 5 & 18.5 & 0 & 0.0 & 0 & 0.0 & 0 & 0.0 & \\
\hline GG & 19 & 15 & 78.9 & 1 & 5.3 & 2 & 10.5 & 1 & 5.3 & & 17 & 89.5 & 0 & 0.0 & 1 & 5.3 & 0 & 0.0 & 1 & 5.3 & \\
\hline rs25487 & & & & & & & & & & 0.45 & & & & & & & & & & & 0.22 \\
\hline AA & 11 & 9 & 81.8 & 2 & 18.2 & 0 & 0.0 & 0 & 0.0 & & 8 & 72.7 & 3 & 27.3 & 0 & 0.0 & 0 & 0.0 & 0 & 0.0 & \\
\hline$A / G$ or $G / G$ & 35 & 26 & 74.3 & 3 & 8.6 & 5 & 14.3 & 1 & 2.9 & & 31 & 88.6 & 2 & 5.7 & 1 & 5.3 & 0 & 0 & 1 & 2.9 & \\
\hline rs13181 & & & & & & & & & & 0.71 & & & & & & & & & & & 0.46 \\
\hline $\mathrm{GG}$ & 11 & 9 & 81.8 & 0 & 0.0 & 2 & 18.2 & 0 & 0.0 & & 9 & 81.8 & 1 & 9.1 & 0 & 0.0 & 0 & 0.0 & 1 & 9.1 & \\
\hline GT & 21 & 15 & 71.4 & 3 & 14.3 & 2 & 9.5 & 1 & 4.8 & & 19 & 90.5 & 2 & 9.5 & 0 & 0.0 & 0 & 0.0 & 0 & 0.0 & \\
\hline$\pi$ & 15 & 12 & 80.0 & 2 & 13.3 & 1 & 6.7 & 0 & 0.0 & & 12 & 80.0 & 2 & 13.3 & 1 & 6.7 & 0 & 0.0 & 0 & 0.0 & \\
\hline rs13181 & & & & & & & & & & 0.81 & & & & & & & & & & & 0.42 \\
\hline $\mathrm{G} / \mathrm{G}$ or $\mathrm{G} / \mathrm{T}$ & 32 & 24 & 75.0 & 3 & 9.4 & 4 & 12.5 & 1 & 3.1 & & 28 & 87.5 & 3 & 9.4 & 0 & 0.0 & 0 & 0.0 & 1 & 3.1 & \\
\hline$\pi$ & 15 & 12 & 80.0 & 2 & 13.3 & 1 & 6.7 & 1 & 2.1 & & 12 & 80.0 & 2 & 13.3 & 1 & 6.7 & 0 & 0.0 & 0 & 0.0 & \\
\hline rs13181 & & & & & & & & & & 0.45 & & & & & & & & & & & 0.3 \\
\hline $\mathrm{G} / \mathrm{T}$ or $\mathrm{T} / \mathrm{T}$ & 36 & 27 & 75.0 & 5 & 13.9 & 3 & 8.3 & 1 & 2.8 & & 31 & 86.1 & 4 & 11.1 & 1 & 2.8 & 0 & 0.0 & 0 & 0.0 & \\
\hline GG & 11 & 9 & 81.8 & 0 & 0.0 & 2 & 18.2 & 0 & 0.0 & & 9 & 81.8 & 1 & 9.1 & 0 & 0.0 & 0 & 0.0 & 1 & 9.1 & \\
\hline rs1799793 & & & & & & & & & & 0.58 & & & & & & & & & & & 0.17 \\
\hline AA & 6 & 5 & 83.3 & 0 & 0.0 & 1 & 16.7 & 0 & 0 & & 5 & 83.3 & 0 & 0.0 & 0 & 0.0 & 0 & 0.0 & 1 & 16.7 & \\
\hline$A G$ & 20 & 16 & 80.0 & 1 & 5.0 & 2 & 10.0 & 1 & 5.0 & & 18 & 90.0 & 2 & 10.0 & 0 & 0.0 & 0 & 0.0 & 0 & 0.0 & \\
\hline$G G$ & 19 & 13 & 68.4 & 4 & 21.1 & 2 & 10.5 & 0 & 0.0 & & 15 & 78.9 & 3 & 15.8 & 1 & 5.3 & 0 & 0.0 & 0 & 0.0 & \\
\hline rs1799793 & & & & & & & & & & 0.27 & & & & & & & & & & & 0.41 \\
\hline$A / A$ or $A / G$ & 26 & 21 & 80.8 & 1 & 3.8 & 3 & 11.5 & 1 & 3.8 & & 23 & 88.5 & 2 & 7.7 & 0 & 0.0 & 0 & 0.0 & 1 & 3.8 & \\
\hline GG & 19 & 13 & 68.4 & 4 & 21.1 & 2 & 10.5 & 0 & 0.0 & & 15 & 78.9 & 3 & 15.8 & 1 & 5.3 & 0 & 0.0 & 0 & 0.0 & \\
\hline rs1799793 & & & & & & & & & & 0.76 & & & & & & & & & & & 0.06 \\
\hline A/A & 6 & 5 & 83.3 & 0 & 0.0 & 1 & 16.7 & 0 & 0.0 & & 5 & 83.3 & 0 & 0.0 & 0 & 0.0 & 0 & 0.0 & 1 & 16.7 & \\
\hline $\mathrm{A} / \mathrm{G}$ or $\mathrm{G} / \mathrm{G}$ & 39 & 29 & 74.4 & 5 & 12.8 & 4 & 10.3 & 1 & 2.6 & & 33 & 84.6 & 5 & 12.8 & 1 & 2.6 & 0 & 0.0 & 0 & 0.0 & \\
\hline rs11615 & & & & & & & & & & 0.95 & & & & & & & & & & & 0.09 \\
\hline$T / T$ or $T / C$ & 38 & 29 & 76.3 & 4 & 10.5 & 4 & 10.5 & 1 & 2.6 & & 32 & 84.2 & 5 & 13.2 & 1 & 2.6 & 0 & 0.0 & 0 & 0.0 & \\
\hline $\mathrm{C} / \mathrm{C}$ & 7 & 5 & 71.4 & 1 & 14.3 & 1 & 14.3 & 0 & 0.0 & & 6 & 85.7 & 0 & 0.0 & 0 & 0.0 & 0 & 0.0 & 1 & 14.3 & \\
\hline rs3212986 & & & & & & & & & & 0.54 & & & & & & & & & & & 0.34 \\
\hline $\mathrm{G} / \mathrm{G}$ & 26 & 20 & 76.9 & 2 & 7.7 & 3 & 11.5 & 1 & 3.8 & & 20 & 76.9 & 5 & 19.2 & 0 & 0.0 & 0 & 0.0 & 1 & 3.8 & \\
\hline $\mathrm{G} / \mathrm{T}$ & 17 & 14 & 82.4 & 2 & 11.8 & 1 & 5.9 & 0 & 0.0 & & 16 & 94.1 & 0 & 0.0 & 1 & 5.9 & 0 & 0.0 & 0 & 0.0 & \\
\hline$T / T$ & 3 & 1 & 33.3 & 1 & 33.3 & 1 & 33.3 & 0 & 0.0 & & 3 & 100.0 & 0 & 0.0 & 0 & 0.0 & 0 & 0.0 & 0 & 0.0 & \\
\hline rs3212986 & & & & & & & & & & 0.72 & & & & & & & & & & & 0.1 \\
\hline $\mathrm{T} / \mathrm{T}$ or $\mathrm{G} / \mathrm{T}$ & 20 & 15 & 75.0 & 3 & 15.0 & 2 & 10.0 & 0 & 0.0 & & 19 & 95.0 & 0 & 0.0 & 1 & 5 & 0 & 0.0 & 0 & 0.0 & \\
\hline $\mathrm{G} / \mathrm{G}$ & 26 & 20 & 76.9 & 2 & 7.7 & 3 & 11.5 & 1 & 3.8 & & 20 & 76.9 & 5 & 19.2 & 0 & 0.0 & 0 & 0.0 & 1 & 3.8 & \\
\hline rs3212986 & & & & & & & & & & 0.28 & & & & & & & & & & & 0.9 \\
\hline $\mathrm{G} / \mathrm{G}$ or $\mathrm{G} / \mathrm{T}$ & 43 & 34 & 79.1 & 4 & 9.3 & 4 & 9.3 & 1 & 2.3 & & 36 & 83.7 & 5 & 11.6 & 1 & 2.3 & 0 & 0.0 & 1 & 2.3 & \\
\hline $\mathrm{T} / \mathrm{T}$ & 3 & 1 & 33.3 & 1 & 33.3 & 1 & 33.3 & 0 & 0.0 & & 3 & 100 & 0 & 0.0 & 0 & 0.0 & 0 & 0.0 & 0 & 0.0 & \\
\hline rs1805087 & & & & & & & & & & 0.07 & & & & & & & & & & & 0.99 \\
\hline A/A & 34 & 27 & 79.4 & 4 & 11.8 & 3 & 8.8 & 0 & 0.0 & & 28 & 82.4 & 4 & 11.8 & 1 & 2.9 & 0 & 0.0 & 1 & 2.9 & \\
\hline$A / G$ & 11 & 8 & 72.7 & 1 & 9.1 & 1 & 9.1 & 1 & 9.1 & & 10 & 90.9 & 1 & 9.1 & 0 & 0.0 & 0 & 0.0 & 0 & 0.0 & \\
\hline $\mathrm{G} / \mathrm{G}$ & 1 & 0 & 0.0 & 0 & 0.0 & 1 & 100 & 0 & 0.0 & & 1 & 100 & 0 & 0.0 & 0 & 0.0 & 0 & 0.0 & 0 & 0.0 & \\
\hline rs1805087 & & & & & & & & & & 0.31 & & & & & & & & & & & 0.83 \\
\hline A/A & 34 & 27 & 79.4 & 4 & 11.8 & 3 & 8.8 & 0 & 0.0 & & 28 & 82.4 & 4 & 11.8 & 1 & 2.9 & 0 & 0.0 & 1 & 2.9 & \\
\hline$A / G$ or $G / G$ & 12 & 8 & 66.7 & 1 & 8.3 & 2 & 16.7 & 1 & 8.3 & & 11 & 91.7 & 1 & 8.3 & 0 & 0.0 & 0 & 0.0 & 0 & 0.0 & \\
\hline rs1801019 & & & & & & & & & & 0.22 & & & & & & & & & & & 0.30 \\
\hline $\mathrm{c} / \mathrm{C}$ & 8 & 7 & 87.5 & 0 & 0.0 & 1 & 12.5 & 0 & 0.0 & & 8 & 100.0 & 0 & 0.0 & 0 & 0.0 & 0 & 0.0 & 0 & 0.0 & \\
\hline C/G & 9 & 6 & 66.7 & 0 & 0.0 & 2 & 22.2 & 1 & 11.1 & & 8 & 88.9 & 0 & 0.0 & 1 & 11.1 & 0 & 0.0 & 0 & 0.0 & \\
\hline $\mathrm{G} / \mathrm{G}$ & 29 & 23 & 79.3 & 4 & 13.8 & 2 & 6.9 & 0 & 0.0 & & 24 & 82.8 & 4 & 13.8 & 0 & 0.0 & 0 & 0.0 & 1 & 3.4 & \\
\hline rs1801019 & & & & & & & & & & 0.76 & & & & & & & & & & & 0.69 \\
\hline $\mathrm{G} / \mathrm{G}$ or $\mathrm{C} / \mathrm{G}$ & 38 & 29 & 76.3 & 4 & 10.5 & 4 & 10.5 & 1 & 2.6 & & 32 & 84.2 & 4 & 10.5 & 1 & 2.6 & 0 & 0.0 & 1 & 2.6 & \\
\hline $\mathrm{C} / \mathrm{C}$ & 8 & 7 & 87.5 & 0 & 0.0 & 1 & 12.5 & 0 & 0.0 & & 8 & 100.0 & 0 & 0.0 & 0 & 0.0 & 0 & 0.0 & 0 & 0.0 & \\
\hline rs1801019 & & & & & & & & & & 0.16 & & & & & & & & & & & 0.19 \\
\hline $\mathrm{C} / \mathrm{C}$ or $\mathrm{G} / \mathrm{C}$ & 17 & 13 & 76.5 & 0 & 0.0 & 3 & 17.6 & 1 & 5.9 & & 16 & 94.1 & 0 & 0.0 & 1 & 5.9 & 0 & 0.0 & 0 & 0.0 & \\
\hline $\mathrm{G} / \mathrm{G}$ & 29 & 23 & 79.3 & 4 & 13.8 & 2 & 6.9 & 0 & 0.0 & & 24 & 82.8 & 4 & 13.8 & 0 & 0.0 & 0 & 0.0 & 1 & 3.4 & \\
\hline TS5utrTR & & & & & & & & & & 0.07 & & & & & & & & & & & 0.21 \\
\hline A (low) & 30 & 23 & 76.7 & 5 & 16.7 & 2 & 6.7 & 0 & 0.0 & & 25 & 83.3 & 4 & 13.3 & 0 & 0.0 & 0 & 0.0 & 1 & 3.3 & \\
\hline B (high) & 12 & 8 & 66.7 & 0 & 0.0 & 3 & 25.0 & 1 & 8.3 & & 11 & 91.7 & 0 & 0.0 & 1 & 8.3 & 0 & 0.0 & 0 & 0.0 & \\
\hline rs16430del & & & & & & & & & & 0.08 & & & & & & & & & & & 0.69 \\
\hline$-/$ & 7 & 6 & 85.7 & 0 & 0.0 & 0 & 0.0 & 1 & 14.3 & & 7 & 100.0 & 0 & 0.0 & 0 & 0.0 & 0 & 0.0 & 0 & 0.0 & \\
\hline$+/-$ & 16 & 14 & 87.5 & 1 & 6.3 & 1 & 6.3 & 0 & 0.0 & & 13 & 81.3 & 2 & 12.5 & 1 & 6.3 & 0 & 0.0 & 0 & 0.0 & \\
\hline$+/+$ & 19 & 11 & 57.9 & 4 & 21.1 & 4 & 21.1 & 0 & 0.0 & & 16 & 84.2 & 2 & 10.5 & 0 & 0.0 & 0 & 0.0 & 1 & 5.3 & \\
\hline rs16430 del_both & & & & & & & & & & 0.07 & & & & & & & & & & & 0.71 \\
\hline 0 & 35 & 25 & 71.4 & 5 & 14.3 & 5 & 14.3 & 0 & 0.0 & & 29 & 82.9 & 4 & 11.4 & 1 & 2.9 & 0 & 0.0 & 1 & 2.9 & \\
\hline 1 & 7 & 6 & 85.7 & 0 & 0.0 & 0 & 0.0 & 1 & 14.3 & & 7 & 100.0 & 0 & 0.0 & 0 & 0.0 & 0 & 0.0 & 0 & 0.0 & \\
\hline
\end{tabular}

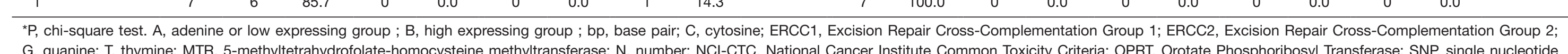
G, guanine; T, thymine; MTR, 5-methyltetrahydrofolate-homocysteine methyltransferase; N, number; NCI-CTC, National Cancer Institute Common Toxicity Criteria; OPRT, Orotate Phosphoribosyl Transferase; SNP, single nucleotide
polymorphism; TS3utrdel, thymidylate synthase: 6-bp-deletion in the in the 3' untranslated regulatory region; TS5utr tandem repeat, thymidylate synthase: 28-bp-tandem repeats in the 5' untranslated region, UMPS, uridine monophosphate synthetase; XRCC1, X-Ray Repair Complementing Defective Repair in Chinese Hamster Cells 1.
moll 
Table S4 Association of maximal hematological toxicity (leukopenia, neutropenia) according to NCI-CTC (version 4) with SNPs of TS, XRCC1, UMPS (OPRT), MTR, ERCC1 and ERCC2

Leukopenia grade $\quad$ Neutropenia grade

\begin{tabular}{|c|c|c|c|c|c|c|c|c|c|c|c|c|c|c|c|c|c|c|c|c|c|c|c|}
\hline \multirow{3}{*}{ SNP } & \multirow{3}{*}{$\mathrm{N}$} & & \\
\hline & & \multicolumn{2}{|c|}{0} & \multicolumn{2}{|c|}{1} & \multicolumn{2}{|c|}{2} & \multicolumn{2}{|c|}{3} & \multicolumn{2}{|c|}{4} & \multirow{2}{*}{ P value } & \multicolumn{2}{|c|}{0} & \multicolumn{3}{|c|}{1} & \multicolumn{2}{|c|}{2} & \multicolumn{2}{|c|}{3} & \multicolumn{2}{|c|}{4} \\
\hline & & $\mathrm{n}$ & $\%$ & $\mathrm{n}$ & $\%$ & $n$ & $\%$ & $\mathrm{n}$ & $\%$ & $\mathrm{n}$ & $\%$ & & $\mathrm{n}$ & $\%$ & & & $\%$ & $\mathrm{n}$ & $\%$ & $\mathrm{n}$ & $\%$ & $\mathrm{n}$ & $\%$ \\
\hline rs25487 & & & & & & & & & & & & 0.11 & & & & & & & & & & & \\
\hline $\mathrm{A} / \mathrm{A}$ & 11 & 1 & 9.1 & 1 & 9.1 & 5 & 45.5 & 4 & 36.4 & 0 & 0.0 & & 6 & 54. & & & 0.0 & 0 & 0.0 & 3 & 27.3 & 2 & 18.2 \\
\hline $\mathrm{A} / \mathrm{G}$ & 16 & 4 & 25.0 & 6 & 37.5 & 3 & 18.8 & 3 & 18.8 & 0 & 0.0 & & 10 & 62. & & & 12.5 & 1 & 6.3 & 2 & 12.5 & 1 & 6.3 \\
\hline $\mathrm{G} / \mathrm{G}$ & 19 & 5 & 26.3 & 1 & 5.3 & 8 & 42.1 & 3 & 15.8 & 2 & 10.5 & & 11 & 57. & & & 0.0 & 2 & 10.5 & 4 & 21.1 & 2 & 10.5 \\
\hline rs25487 & & & & & & & & & & & & 0.14 & & & & & & & & & & & \\
\hline$A / A$ or $A / G$ & 27 & 5 & 18.5 & 7 & 25.9 & 8 & 29.6 & 7 & 25.9 & 0 & 0.0 & & 16 & 59. & & & 7.4 & 1 & 3.7 & 5 & 18.5 & 3 & 11. \\
\hline GG & 19 & 5 & 26.3 & 1 & 5.3 & 8 & 42.1 & 3 & 15.8 & 2 & 10.5 & & 11 & 57. & & & 0.0 & 2 & 10.5 & 4 & 21.1 & 2 & 10. \\
\hline rs25487 & & & & & & & & & & & & 0.39 & & & & & & & & & & & \\
\hline AA & 11 & 1 & 9.1 & 1 & 9.1 & 5 & 45.5 & 4 & 36.4 & 0 & 0.0 & & 6 & 54. & & & 0.0 & 0 & 0.0 & 3 & 27.3 & 2 & 18.2 \\
\hline$A / G$ or $G / G$ & 35 & 9 & 25.7 & 7 & 20.0 & 11 & 31.4 & 6 & 17.1 & 2 & 5.7 & & 21 & 60. & & & 5.7 & 3 & 8.6 & 6 & 17.1 & 3 & 8.6 \\
\hline rs13181 & & & & & & & & & & & & 0.43 & & & & & & & & & & & \\
\hline GG & 11 & 2 & 18.2 & 2 & 18.2 & 5 & 45.5 & 1 & 9.1 & 1 & 9.1 & & 4 & 36. & & & 0.0 & 2 & 18.2 & 4 & 36.4 & 1 & 9.1 \\
\hline GT & 21 & 6 & 28.6 & 5 & 23.8 & 7 & 33.3 & 3 & 14.3 & 0 & 0.0 & & 16 & 76. & & & 4.8 & 1 & 4.8 & 2 & 9.5 & 1 & 4.8 \\
\hline$\pi$ & 15 & 3 & 20.0 & 1 & 6.7 & 4 & 26.7 & 6 & 40.0 & 1 & 6.7 & & 8 & 53. & & & 6.7 & 0 & 0.0 & 3 & 20.0 & 3 & 20. \\
\hline rs13181 & & & & & & & & & & & & 0.22 & & & & & & & & & & & \\
\hline $\mathrm{G} / \mathrm{G}$ or $\mathrm{G} / \mathrm{T}$ & 32 & 8 & 25 & 7 & 21.9 & 12 & 37.5 & 4 & 12.5 & 1 & 3.1 & & 20 & 62. & & & 3.1 & 3 & 9.4 & 6 & 18.8 & 2 & 6.3 \\
\hline$\pi$ & 15 & 3 & 20 & 1 & 6.7 & 4 & 26.7 & 6 & 40.0 & 1 & 6.7 & & 8 & 53. & & & 6.7 & 0 & 0.0 & 3 & 20.0 & 3 & 20. \\
\hline rs 13181 & & & & & & & & & & & & 0.64 & & & & & & & & & & & \\
\hline $\mathrm{G} / \mathrm{T}$ or $\mathrm{T} / \mathrm{T}$ & 36 & 9 & 25.0 & 6 & 16.7 & 11 & 30.6 & 9 & 25.0 & 1 & 2.8 & & 24 & 66. & & & 5.6 & 1 & 2.8 & 5 & 13.9 & 4 & 11. \\
\hline GG & 11 & 2 & 18.2 & 2 & 18.2 & 5 & 45.5 & 1 & 9.1 & 1 & 9.1 & & 4 & 36. & & & 0.0 & 2 & 18.2 & 4 & 36.4 & 1 & 9.1 \\
\hline rs1799793 & & & & & & & & & & & & 0.55 & & & & & & & & & & & \\
\hline AA & 6 & 1 & 16.7 & 0 & 0.0 & 3 & 50.0 & 1 & 16.7 & 1 & 16.7 & & 5 & 83. & & & 0.0 & 1 & 16.7 & 0 & 0.0 & 0 & 0.0 \\
\hline$A G$ & 20 & 5 & 25.0 & 4 & 20.0 & 8 & 40.0 & 3 & 15.0 & 0 & 0.0 & & 13 & 65 & & & 5.0 & 1 & 5.0 & 4 & 20.0 & 1 & 5.0 \\
\hline GG & 19 & 3 & 15.8 & 4 & 21.1 & 5 & 26.3 & 6 & 31.6 & 1 & 5.3 & & 8 & 42. & & & 5.3 & 1 & 5.3 & 5 & 26.3 & 4 & 21. \\
\hline rs1799793 & & & & & & & & & & & & 0.62 & & & & & & & & & & & \\
\hline$A / A$ or $A / G$ & 26 & 6 & 23.1 & 4 & 15.4 & 11 & 42.3 & 4 & 15.4 & 1 & 3.8 & & 18 & 69. & & & 3.8 & 2 & 7.7 & 4 & 15.4 & 1 & 3.8 \\
\hline GG & 19 & 3 & 15.8 & 4 & 21.1 & 5 & 26.3 & 6 & 31.6 & 1 & 5.3 & & 8 & 42. & & & 5.3 & 1 & 5.3 & 5 & 26.3 & 4 & 21. \\
\hline rs1799793 & & & & & & & & & & & & 0.39 & & & & & & & & & & & \\
\hline $\mathrm{A} / \mathrm{A}$ & 6 & 1 & 16.7 & 0 & 0.0 & 3 & 50.0 & 1 & 16.7 & 1 & 16.7 & & 5 & 83. & & & 0.0 & 1 & 16.7 & 0 & 0.0 & 0 & 0.0 \\
\hline$A / G$ or $G / G$ & 39 & 8 & 20.5 & 8 & 20.5 & 13 & 33.3 & 9 & 23.1 & 1 & 2.6 & & 21 & 53. & & & 5.1 & 2 & 5.1 & 9 & 23.1 & 5 & 12.8 \\
\hline rs 11615 & & & & & & & & & & & & 0.3 & & & & & & & & & & & \\
\hline $\mathrm{C} / \mathrm{C}$ or $\mathrm{T} / \mathrm{C}$ & 30 & 9 & 30.0 & 5 & 16.7 & 8 & 26.7 & 6 & 20.0 & 2 & 6.7 & & 19 & 63. & & & 0.0 & 2 & 6.7 & 7 & 23.3 & 2 & 6.7 \\
\hline$T / T$ & 15 & 1 & 6.7 & 3 & 20.0 & 7 & 46.7 & 4 & 26.7 & c & 0.0 & & 8 & 53. & & & 13.3 & 1 & 6.7 & 2 & 13.3 & 2 & 13. \\
\hline rs3212986 & & & & & & & & & & & & 0.6 & & & & & & & & & & & \\
\hline $\mathrm{G} / \mathrm{G}$ & 26 & 7 & 26.9 & 4 & 15.4 & 8 & 30.8 & 5 & 19.2 & 2 & 7.7 & & 14 & 53. & & & 7.7 & 1 & 3.8 & 6 & 23.1 & 3 & 11.5 \\
\hline $\mathrm{G} / \mathrm{T}$ & 17 & 4 & 23.5 & 3 & 17.6 & 6 & 35.3 & 4 & 23.5 & c & 0.0 & & 11 & 64. & & & 0.0 & 1 & 5.9 & 4 & 23.5 & 1 & 5.9 \\
\hline$T / T$ & 3 & 0 & 0.0 & 1 & 33.3 & 0 & 0.0 & 2 & 66.7 & $c$ & 0 & & 2 & 66. & & & 0.0 & 0 & 0.0 & 0 & 0.0 & 1 & 33. \\
\hline
\end{tabular}

$\begin{array}{cccccccccccc}\mathrm{rs} 3212986 & & & & & & & & & & & \\ \mathrm{~T} / \mathrm{T} \text { or } \mathrm{G} / \mathrm{T} & 20 & 4 & 20.0 & 4 & 20.0 & 6 & 30.0 & 6 & 30.0 & 0 & 0.0\end{array}$

$\begin{array}{llllllllllll}\mathrm{G} / \mathrm{G} & 26 & 7 & 26.9 & 4 & 15.4 & 8 & 30.8 & 5 & 19.2 & 2 & 7.7\end{array}$

rs3212986

$\begin{array}{llllllllllll}\mathrm{G} / \mathrm{G} \text { or } \mathrm{G} / \mathrm{T} & 43 & 11 & 25.6 & 7 & 16.3 & 14 & 32.6 & 9 & 20.9 & 2 & 4.7\end{array}$

$\begin{array}{llllllllllll}\mathrm{T} / \mathrm{T} & 3 & 0 & 0.0 & 1 & 33.3 & 0 & 0.0 & 2 & 66.7 & 0 & 0.0\end{array}$

rs 1805087

$\begin{array}{llllllllllll}\text { A/A } & 34 & 8 & 23.5 & 6 & 17.6 & 11 & 32.4 & 8 & 23.5 & 1 & 2.9\end{array}$

$\begin{array}{llllllllllll}\mathrm{A} / \mathrm{G} & 11 & 2 & 18.2 & 1 & 9.1 & 4 & 36.4 & 3 & 27.3 & 1 & 9.1\end{array}$

$\begin{array}{llllllllllll}\mathrm{G} / \mathrm{G} & 1 & 0 & 0.0 & 1 & 100.0 & 0.0 & 0.0 & 0 & 0.0 & 0 & 0 \\ \text { rs } 1805087 & & & & & & & & & & & \end{array}$

$\begin{array}{llllllllllll}\text { A/A } & 34 & 8 & 23.5 & 6 & 17.6 & 11 & 32.4 & 8 & 23.5 & 1 & 2.9\end{array}$

$\begin{array}{cccccccccccc}\mathrm{A} / \mathrm{G} \text { or G/G } & 12 & 2 & 16.7 & 2 & 16.7 & 4 & 33.3 & 3 & 25.0 & 1 & 8.3 \\ \mathrm{rs} 1805087 & & & & & & & & & & & \end{array}$

$\begin{array}{llllllllllll}\text { A/A or A/G } & 45 & 10 & 22.2 & 7 & 15.6 & 15 & 33.3 & 11 & 24.4 & 2 & 4.4\end{array}$

$\begin{array}{llllllllllll}\mathrm{G} / \mathrm{G} & 1 & 0 & 0.0 & 1 & 100.0 & 0 & 0.0 & 0 & 0.0 & 0 & 0.0\end{array}$

rs1801019

$\begin{array}{llllllllllll}\mathrm{C} / \mathrm{C} & 8 & 1 & 12.5 & 2 & 25.0 & 3 & 37.5 & 2 & 25.0 & 0 & 0.0\end{array}$

$\begin{array}{lccccccccccc}\mathrm{C} / \mathrm{G} & 9 & 0 & 0.0 & 0 & 0.0 & 6 & 66.7 & 3 & 33.3 & 0 & 0.0 \\ \mathrm{G} / \mathrm{G} & 29 & 10 & 34.5 & 6 & 20.7 & 7 & 24.1 & 5 & 17.2 & 1 & 3.4\end{array}$

rs1801019

$\begin{array}{llllllllllll}\mathrm{G} / \mathrm{G} \text { or } \mathrm{C} / \mathrm{G} & 38 & 10 & 26.3 & 6 & 15.8 & 13 & 34.2 & 8 & 21.1 & 1 & 2.6\end{array}$ $\begin{array}{llllllllllll}\mathrm{C} / \mathrm{C} & 8 & 1 & 12.5 & 2 & 25.0 & 3 & 37.5 & 2 & 25.0 & 0 & 0.0\end{array}$ rs 1801019

$\begin{array}{llllllllllll}\mathrm{C} / \mathrm{C} \text { or } \mathrm{G} / \mathrm{C} & 17 & 1 & 5.9 & 2 & 11.8 & 9 & 52.9 & 5 & 29.4 & 0 & 0.0\end{array}$ $\begin{array}{llllllllllll}\mathrm{G} / \mathrm{G} & 29 & 10 & 34.5 & 6 & 20.7 & 7 & 24.1 & 5 & 17.2 & 1 & 3.4\end{array}$

TS5utrTR

$\begin{array}{llllllllllll}2 \mathrm{R} / 2 \mathrm{R} & 12 & 3 & 25.0 & 1 & 8.3 & 3 & 25.0 & 3 & 25.0 & 2 & 16.7\end{array}$

$\begin{array}{llllllllllll}2 \mathrm{R} / 3 \mathrm{R} & 18 & 1 & 5.6 & 5 & 27.8 & 7 & 38.9 & 5 & 27.8 & 0 & 0.0\end{array}$

$\begin{array}{llllllllllll}3 \mathrm{R} / 3 \mathrm{R} & 12 & 4 & 33.3 & 2 & 16.7 & 4 & 33.3 & 2 & 16.7 & 0 & 0.0\end{array}$

$\begin{array}{llllllllllll}\text { TS5utrTR } & & & & & & & & & & & \\ \text { A (low) } & 30 & 4 & 13.3 & 6 & 20.0 & 10 & 33.3 & 8 & 26.7 & 2 & 6.7\end{array}$

$\begin{array}{llllllllllll}\text { B (high) } & 12 & 4 & 33.3 & 2 & 16.7 & 4 & 33.3 & 2 & 16.7 & 0 & 0.0\end{array}$

$\begin{array}{llllllllllll}\text { rs16430del } & & & & & & & & & & \\ -/- & 7 & 1 & 14.3 & 2 & 28.6 & 4 & 57.1 & 0 & 0.0 & 0 & 0.0\end{array}$

$\begin{array}{llllllllllll}+/- & 16 & 2 & 12.5 & 2 & 12.5 & 7 & 43.8 & 4 & 25.0 & 1 & 6.3 \\ + & 1 & 5 & 203 & 4 & 21.1 & 3 & 15.8 & 0 & 31.0 & 1 & 5.3\end{array}$ rs16430 del_

0.65

$\begin{array}{llllllllll}13 & 65.0 & 0 & 0.0 & 1 & 5.0 & 4 & 20.0 & 2 & 10.0\end{array}$ $\begin{array}{llllllllll}14 & 53.8 & 2 & 7.7 & 1 & 3.8 & 6 & 23.1 & 3 & 11.5\end{array}$

0.31

$\begin{array}{llllllllll}25 & 58.1 & 2 & 4.7 & 2 & 4.7 & 10 & 23.3 & 4 & 9.3\end{array}$

0.63

$\begin{array}{llllllllll}20 & 58.8 & 2 & 5.9 & 2 & 5.9 & 7 & 20.6 & 3 & 8.8\end{array}$

$\begin{array}{llllllllll}8 & 72.8 & 0 & 0.0 & 0 & 0.0 & 2 & 18.2 & 1 & 9.1\end{array}$

0.94

$\begin{array}{llllllllll}20 & 58.8 & 2 & 5.9 & 2 & 5.9 & 7 & 20.6 & 3 & 8.8\end{array}$

0.30

$\begin{array}{llllllllll}28 & 62.2 & 2 & 4.4 & 2 & 4.4 & 9 & 20.0 & 4 & 8.9\end{array}$

0.20

$\begin{array}{llllllllll}4 & 50.0 & 0 & 0.0 & 1 & 12.5 & 1 & 12.5 & 2 & 25.0\end{array}$

$\begin{array}{llllllllll}6 & 66.7 & 0 & 0.0 & 0 & 0.0 & 3 & 33.3 & 0 & 0.0\end{array}$

$\begin{array}{llllllllll}18 & 62.1 & 2 & 6.9 & 2 & 6.9 & 6 & 20.7 & 1 & 3.4\end{array}$

$\begin{array}{llllllllll}24 & 63.2 & 2 & 5.3 & 2 & 5.3 & 9 & 23.7 & 1 & 2.6\end{array}$

$\begin{array}{llllllllll}10 & 58.8 & 0 & 0 & 1 & 5.9 & 4 & 23.5 & 2 & 11.8\end{array}$

$\begin{array}{llllllllll}18 & 62.1 & 2 & 6.9 & 2 & 6.9 & 6 & 20.7 & 1 & 3.4\end{array}$

$\begin{array}{llllllllll}9 & 75.0 & 0 & 0 & 0 & 0.0 & 1 & 8.3 & 2 & 16.7\end{array}$ $\begin{array}{llllllllll}9 & 50.0 & 2 & 11.1 & 3 & 16.7 & 2 & 11.1 & 2 & 11.1\end{array}$ 
Table S5 Association of non-hematological toxicity (diarrhea, neuropathy) 0-1 vs. 22 according to NCI-CTC (version 4) with SNPs of TS, XRCC1, UMPS (OPRT), MTR, ERCC1 and ERCC2

\begin{tabular}{|c|c|c|c|c|c|c|c|c|c|c|c|}
\hline \multirow{3}{*}{ SNP } & \multirow{3}{*}{$\mathrm{N}$} & \multicolumn{5}{|c|}{ Diarrhea grade } & \multicolumn{5}{|c|}{ Neuropathy grade } \\
\hline & & \multicolumn{2}{|c|}{$0-1$} & \multicolumn{2}{|c|}{$\geq 2$} & \multirow{2}{*}{ P value } & \multicolumn{2}{|c|}{$0-1$} & \multicolumn{2}{|c|}{$\geq 2$} & \multirow{2}{*}{ P value* } \\
\hline & & $n$ & $\%$ & $n$ & $\%$ & & $n$ & $\%$ & $n$ & $\%$ & \\
\hline rs25487 & & & & & & 0.33 & & & & & 0.18 \\
\hline $\mathrm{A} / \mathrm{A}$ & 11 & 6 & 54.5 & 5 & 45.5 & & 8 & 72.7 & 3 & 27.3 & \\
\hline
\end{tabular}

$A / G$

$\mathrm{G} / \mathrm{G}$

$\begin{array}{lll}54.5 & 5 & 45.5 \\ 81.3 & 3 & 18.8 \\ 68.4 & 6 & 31.6\end{array}$

rs25487

A/A or $A / G$

GG

rs25487

AA

rs13181

$\mathrm{GG}$

$\pi$

$\mathrm{G} / \mathrm{G}$ or $\mathrm{G} / \mathrm{T}$

$\begin{array}{lllll}32 & 25 & 78.1 & 7 & 21.9\end{array}$

rs13181

$\mathrm{G} / \mathrm{T}$ or $\mathrm{T} / \mathrm{T}$

GG

rs1799793

AA

AG

GG

rs1799793

A/A or A/G

GG

rs1799793

A/A

A/G or $G / G$

rs11615

$\mathrm{C} / \mathrm{C}$

T/C

$T / T$

rs11615

$\mathrm{C} / \mathrm{C}$ or $\mathrm{T} / \mathrm{C}$

$\mathrm{T} / \mathrm{T}$

TS 11615 or T/C

$\mathrm{C} / \mathrm{C}$

rs3212986

$\begin{array}{llllll}\mathrm{G} / \mathrm{G} & 26 & 18 & 69.2 & 8 & 30.8 \\ \mathrm{G} / \mathrm{T} & 17 & 11 & 64.7 & 6 & 35.3\end{array}$

$\begin{array}{llllll}\mathrm{T} / \mathrm{T} & 3 & 2 & 66.7 & 1 & 33.3\end{array}$

rs3212986

$\begin{array}{llllll}\mathrm{T} / \mathrm{T} \text { or } \mathrm{G} / \mathrm{T} & 20 & 13 & 65.0 & 7 & 35.0\end{array}$

$\begin{array}{llllll}\mathrm{G} / \mathrm{G} & 26 & 18 & 69.2 & 8 & 30.8\end{array}$

rs3212986

$\begin{array}{llllll}\mathrm{G} / \mathrm{G} \text { or } \mathrm{G} / \mathrm{T} & 43 & 29 & 67.4 & 14 & 32.6\end{array}$

$\begin{array}{llllll}\mathrm{T} T \mathrm{~T} & 3 & 2 & 66.7 & 1 & 33.3\end{array}$

rs1805087

$\begin{array}{llllll}\text { A/A or A/G } & 45 & 30 & 66.7 & 15 & 33.3\end{array}$

$\begin{array}{llllll}\mathrm{G} / \mathrm{G} & 1 & 1 & 100.0 & 0 & 0.0\end{array}$

rs1801019

$\mathrm{C} / \mathrm{C}$

$\mathrm{C} / \mathrm{G}$

$\mathrm{G} / \mathrm{G}$

rs1801019

G/G or C/G

$\mathrm{C} / \mathrm{C}$

rs1801019

$\mathrm{C} / \mathrm{C}$ or $\mathrm{G} / \mathrm{C}$

G/G
TS5utrTR

2R/2R

$2 \mathrm{R} / 3 \mathrm{R}$

3R/3R

TS5utrTR

A (low)

$B$ (high)

rs16430del

$-/-$

$+/-$

rs16430 del_both

$\begin{array}{lll}50.0 & 4 & 50.0\end{array}$

$\begin{array}{ccccc}8 & 4 & 50.0 & 4 & 50.0 \\ 9 & 6 & 66.7 & 3 & 33.3 \\ 29 & 21 & 72.4 & 8 & 27.6\end{array}$

1.00

0.11

$\begin{array}{llll}21 & 77.8 & 6 & 22.2 \\ 10 & 52.6 & 9 & 47.4\end{array}$

0.27

$\begin{array}{cccc}8 & 72.7 & 3 & 27.3 \\ 23 & 65.7 & 12 & 34.4\end{array}$

0.21

0.72

1.00

0.65 
Table S8 Association of progression free survival (PFS) and overall survival (OS) with SNPs of TS, XRCC1, UMPS (OPRT), MTR, ERCC1 and ERCC2

\begin{tabular}{|c|c|c|c|c|c|c|c|c|c|c|c|c|}
\hline & & & & PFS & & & & & & os & & \\
\hline SINP & $\mathbb{N}$ & median $\pm S E$ & $95 \% \mathrm{Cl}$ & Pvalue & $\mathrm{HR}$ & $95 \% \mathrm{Cl}$ & Pvalue ${ }^{+}$ & median $\pm \mathrm{SE}$ & $95 \% \mathrm{Cl}$ & Pvalue ${ }^{t}$ & $\mathrm{HR}$ & $95 \% \mathrm{Cl}$ \\
\hline rs25487 & & & & 0.57 & & & & & & 0.79 & & \\
\hline $\mathrm{A} / \mathrm{A}$ & 11 & $26.36 \pm 5.23^{*}$ & $16.11-36.62$ & & ref. & ref. & - & $28.33 \pm 4.58^{*}$ & $19.35-37.31$ & & ref. & ref. \\
\hline$A / G$ & 16 & $19.57 \pm 3.78$ & $12.17-26.98$ & & 1.12 & $0.38-3.36$ & 0.83 & $32.73 \pm 6.45$ & $20.08-45.38$ & & 1.21 & $0.39-3.70$ \\
\hline$G / G$ & 19 & $31.41 \pm N A$ & NA & & 1.61 & $0.65-3.99$ & 0.31 & $30.82 \pm 3.08^{*}$ & $24.78-36.86$ & & 1.40 & $0.54-3.66$ \\
\hline rs25487 & & & & 0.42 & & & & & & 0.53 & & \\
\hline$A / A$ or $A / G$ & 27 & $19.57 \pm 8.20$ & $3.51-35.64$ & & 1.4 & $0.61-3.22$ & 0.42 & $32.73 \pm 5.26$ & $22.42-43.04$ & & 1.33 & $0.55-3.17$ \\
\hline$G / G$ & 19 & $31.41 \pm \mathrm{NA}$ & NA & & ref. & ref. & - & $30.81 \pm 3.08^{*}$ & $24.78-36.86$ & & ref. & ref. \\
\hline rs25487 & & & & 0.84 & & & & & & 0.96 & & \\
\hline AA & 11 & $26.36 \pm 5.23^{\star}$ & $16.11-36.62$ & & ref. & ref. & - & $28.33 \pm 4.58^{*}$ & $19.35-37.31$ & & ref. & ref. \\
\hline$A / G$ or $G / G$ & 35 & $22.13 \pm 7.46$ & $7.53-36.75$ & & 0.90 & $0.34-2.43$ & 0.84 & $34.41 \pm 3.72$ & $27.11-41.71$ & & 1.02 & $0.38-2.79$ \\
\hline rs13181 & & & & 0.50 & & & & & & 0.87 & & \\
\hline $\mathrm{GG}$ & 11 & $16.05 \pm 6.54$ & $3.24-28.87$ & & ref. & ref. & - & $39.15 \pm 13.14$ & $13.39-64.90$ & & ref. & ref. \\
\hline GT & 21 & $32.47 \pm N A$ & NA & & 1.29 & $0.48-3.46$ & 0.62 & $30.54 \pm 3.11^{*}$ & $24.45-36.64$ & & 1.05 & $0.36-3.06$ \\
\hline$\pi$ & 15 & $22.01 \pm 3.17$ & $15.80-28.22$ & & 0.72 & $0.28-1.81$ & 0.48 & $34.41 \pm 8.84$ & $17.08-51.73$ & & 0.82 & $0.31-2.14$ \\
\hline rs13181 & & & & 0.78 & & & & & & 0.81 & & \\
\hline $\mathrm{G} / \mathrm{G}$ or $\mathrm{G} / \mathrm{T}$ & 32 & $31.41 \pm 9.85$ & $12.11-50.72$ & & 0.89 & $0.39-2.02$ & 0.78 & $39.15 \pm 6.67$ & $26.06-52.23$ & & 0.90 & $0.38-2.14$ \\
\hline$\pi$ & 15 & $22.01 \pm 3.17$ & $15.80-28.22$ & & ref. & ref. & - & $34.41 \pm 8.84$ & $17.08-51.73$ & & ref. & ref. \\
\hline rs13181 & & & & 0.33 & & & & & & 0.74 & & \\
\hline $\mathrm{G} / \mathrm{T}$ or $\mathrm{T} / \mathrm{T}$ & 36 & $31.41 \pm 8.05$ & $15.63-47.20$ & & 0.65 & $0.27-1.56$ & 0.33 & $30.41 \pm \mathrm{NA}$ & NA & & 0.85 & $0.33-2.17$ \\
\hline GG & 11 & $16.05 \pm 6.54$ & $3.24-28.87$ & & ref. & ref. & - & $39.15 \pm 13.14$ & $13.39-64.27$ & & ref. & ref. \\
\hline rs1799793 & & & & 0.18 & & & & & & 0.20 & & \\
\hline AA & 6 & $7.37 \pm 8.48$ & $0.00-23.99$ & & ref. & ref. & & $11.48 \pm 15.69$ & $0.00-42.24$ & & ref. & ref. \\
\hline$A G$ & 20 & $32.47 \pm \mathrm{NA}$ & NA & & 2.25 & $0.77-6.62$ & 0.14 & $31.61 \pm 3.04^{*}$ & $25.64-37.57$ & & 2.10 & $0.69-6.40$ \\
\hline GG & 19 & $22.01 \pm N A$ & NA & & 0.85 & $0.34-2.10$ & 0.72 & $34.41 \pm N A$ & NA & & 0.79 & $0.30-2.07$ \\
\hline rs1799793 & & & & 0.83 & & & & & & 0.95 & & \\
\hline$A / A$ or $A / G$ & 26 & $22.14 \pm 9.08$ & $4.34-39.94$ & & 1.09 & $0.49-2.47$ & 0.83 & $39.15 \pm 6.31$ & $26.79-51.50$ & & 1.03 & $0.43-2.46$ \\
\hline GG & 19 & $22.01 \pm N A$ & NA & & ref. & ref. & - & $34.41 \pm N A$ & NA & & ref. & ref. \\
\hline rs1799793 & & & & 0.07 & & & & & & 0.08 & & \\
\hline $\mathrm{A} / \mathrm{A}$ & 6 & $7.37 \pm 8.48$ & $0.00-23.99$ & & ref. & ref. & - & $11.48 \pm 15.69$ & $0.00-42.24$ & & ref. & ref. \\
\hline$A / G$ or $G / G$ & 39 & $31.41 \pm \mathrm{NA}$ & NA & & 2.44 & $0.91-6.58$ & 0.08 & $30.99 \pm 2.13^{*}$ & $26.81-35.16$ & & 2.38 & $0.87-6.50$ \\
\hline rs11615 & & & & 0.47 & & & & & & 0.83 & & \\
\hline $\mathrm{C} / \mathrm{C}$ & 7 & $19.24 \pm 4.18$ & $11.06-27.43$ & & ref. & ref. & - & $39.15 \pm 0.00$ & NA & & ref. & ref. \\
\hline $\mathrm{T} / \mathrm{C}$ & 23 & $22.01 \pm 3.32$ & $15.50-28.52$ & & 1.67 & $0.47-5.95$ & 0.43 & $28.59 \pm 7.25$ & $14.37-42.80$ & & 1.47 & $0.41-5.27$ \\
\hline$T / T$ & 15 & $26.42 \pm 3.67^{\star}$ & $19.22-33.62$ & & 1.80 & $0.69-4.68$ & 0.23 & $28.51 \pm 3.12^{\star}$ & $22.40-34.63$ & & 1.25 & $0.47-3.35$ \\
\hline rs11615 & & & & 0.22 & & & & & & 0.59 & & \\
\hline $\mathrm{C} / \mathrm{C}$ or $\mathrm{T} / \mathrm{C}$ & 30 & $19.57 \pm 2.79$ & $14.10-25.05$ & & 1.77 & $0.70-4.46$ & 0.23 & $32.73 \pm 6.69$ & $19.61-45.85$ & & 1.3 & $0.50-3.35$ \\
\hline$T / T$ & 15 & $26.42 \pm 3.67^{\star}$ & $19.22-33.62$ & & ref. & ref. & - & $28.51 \pm 3.12^{\star}$ & $22.40-34.63$ & & ref. & ref. \\
\hline rs11615 & & & & 0.80 & & & & & & 0.66 & & \\
\hline$T / T$ or $T / C$ & 38 & $22.14 \pm 7.70$ & $7.06-37.22$ & & 0.87 & $0.30-2.54$ & 0.80 & $32.73 \pm N A$ & NA & & 0.79 & $0.27-2.33$ \\
\hline $\mathrm{c} / \mathrm{C}$ & 7 & $19.24 \pm 4.18$ & $11.06-27.43$ & & ref. & ref. & - & $39.15 \pm 0.00$ & NA & & ref. & ref. \\
\hline rs3212986 & & & & 0.80 & & & & & & 0.91 & & \\
\hline$G / G$ & 26 & $31.41 \pm N A$ & NA & & ref. & ref. & - & $28.83 \pm 2.88^{\star}$ & $23.19-34.47$ & & ref. & ref. \\
\hline $\mathrm{G} / \mathrm{T}$ & 17 & $32.47 \pm 11.61$ & $9.72-55.22$ & & 0.62 & $0.14-2.81$ & 0.54 & $39.15 \pm 3.73$ & $31.83-46.46$ & & 1.44 & $0.19-11.15$ \\
\hline$T / T$ & 3 & $22.01 \pm 17.08$ & $0.00-55.49$ & & 0.60 & $0.13-2.81$ & 0.52 & $28.10 \pm 6.30^{*}$ & $15.75-40.46$ & & 1.25 & $0.16-9.99$ \\
\hline rs3212986 & & & & 0.92 & & & & & & 0.69 & & \\
\hline $\mathrm{T} / \mathrm{T}$ or $\mathrm{G} / \mathrm{T}$ & 20 & $22.14 \pm 8.77$ & $4.95-39.33$ & & 1.04 & $0.46-2.37$ & 0.92 & $39.15 \pm 3.51$ & $32.27-46.02$ & & 0.84 & $0.35-2.00$ \\
\hline$G / G$ & 26 & $31.41 \pm N A$ & NA & & ref. & ref. & - & $28.82 \pm 2.88^{*}$ & 23.19-34.47 & & ref. & ref. \\
\hline rs3212986 & & & & 0.51 & & & & & & & & \\
\hline $\mathrm{G} / \mathrm{G}$ or $\mathrm{G} / \mathrm{T}$ & 43 & $31.41 \pm N A$ & NA & & 0.61 & $0.14-2.64$ & 0.51 & $39.15 \pm 5.33$ & $28.69-49.60$ & 0.77 & 1.36 & $0.18-10.15$ \\
\hline$T / T$ & 3 & $22.01 \pm 17.08$ & $0.00-55.49$ & & ref. & ref. & - & $28.10 \pm 6.30^{*}$ & $15.75-40.46$ & & ref. & ref. \\
\hline rs1805087 & & & & 0.51 & & & & & & 0.58 & & \\
\hline $\mathrm{A} / \mathrm{A}$ & 34 & $N A^{* *}$ & $\mathrm{NA}^{*+}$ & & ref. & ref. & - & $\mathrm{NA}^{* *}$ & $N A^{* *}$ & & ref. & ref. \\
\hline $\mathrm{A} / \mathrm{G}$ & 11 & $N A^{* *}$ & $\mathrm{NA}^{* *}$ & & NA & NA & 0.94 & $\mathrm{NA}^{* *}$ & $N A^{* *}$ & & NA & NA \\
\hline G/G & 1 & $\mathrm{NA}^{* *}$ & $\mathrm{NA}^{*+}$ & & NA & NA & 0.93 & $\mathrm{NA}^{* *}$ & $\mathrm{NA}^{* *}$ & & NA & NA \\
\hline rs1805087 & & & & 0.58 & & & & & & 0.60 & & \\
\hline $\mathrm{A} / \mathrm{A}$ & 34 & $26.71 \pm 2.87^{\star}$ & $21.09-32.33$ & & ref. & ref. & - & $29.79 \pm 2.49^{*}$ & 24.91-34.67 & & ref. & ref. \\
\hline$A / G$ or $G / G$ & 12 & $22.01 \pm 1.70$ & $18.67-25.35$ & & 0.79 & $0.34-1.84$ & 0.58 & $31.02 \pm 3.37$ & $24.42-37.62$ & & 0.79 & $0.32-1.94$ \\
\hline rs1805087 & & & & 0.40 & & & & & & 0.46 & & \\
\hline$A / A$ or $A / G$ & 45 & $N A^{* *}$ & $\mathrm{NA}^{* *}$ & & NA & NA & 0.58 & $\mathrm{NA}^{* *}$ & $\mathrm{NA}^{\text {t* }}$ & & NA & NA \\
\hline$G / G$ & 1 & $\mathrm{NA}^{* *}$ & $\mathrm{NA}^{* *}$ & & ref. & ref. & - & $\mathrm{NA}^{* *}$ & $\mathrm{NA}^{* *}$ & & ref. & ref. \\
\hline rs1801019 & & & & 0.26 & & & & & & 0.36 & & \\
\hline $\mathrm{C} / \mathrm{C}$ & 8 & $22.01 \pm N A$ & NA & & ref. & ref. & - & $30.47 \pm 4.03^{*}$ & $22.58-38.37$ & & ref. & ref. \\
\hline C/G & 9 & $33.00 \pm 4.39^{*}$ & $24.41-41.60$ & & 0.66 & $0.22-1.96$ & 0.45 & $34.56 \pm 3.79^{*}$ & $27.14-41.99$ & & 0.58 & $0.17-2.00$ \\
\hline$G / G$ & 29 & $19.57 \pm 4.99$ & $9.80-29.35$ & & 0.39 & $0.11-1.33$ & 0.13 & $28.59 \pm 7.33$ & $14.23-42.94$ & & 0.46 & $0.13-1.59$ \\
\hline rs1801019 & & & & 0.71 & & & & & & 0.54 & & \\
\hline $\mathrm{G} / \mathrm{G}$ or $\mathrm{C} / \mathrm{G}$ & 38 & $22.14 \pm 7.89$ & $6.68-37.60$ & & 1.23 & $0.42-3.59$ & 0.71 & $32.73 \pm 5.39$ & $22.16-43.30$ & & 1.46 & $0.43-4.98$ \\
\hline $\mathrm{C} / \mathrm{C}$ & 8 & $22.01 \pm \mathrm{NA}$ & NA & & ref. & ref. & - & $30.47 \pm 4.03^{*}$ & $22.58-38.37$ & & ref. & ref. \\
\hline rs1801019 & & & & 0.13 & & & & & & 0.16 & & \\
\hline $\mathrm{C} / \mathrm{C}$ or $\mathrm{G} / \mathrm{C}$ & 17 & $30.83 \pm 3.35^{*}$ & $24.27-37.40$ & & 0.51 & $0.21-1.29$ & 0.13 & $33.81 \pm 2.98^{*}$ & $27.98-39.65$ & & 0.51 & $0.20-1.32$ \\
\hline$G / G$ & 29 & $19.57 \pm 4.99$ & $9.80-29.35$ & & ref. & ref. & - & $28.59 \pm 7.33$ & $14.23-42.94$ & & ref. & ref. \\
\hline TSSutrTR & & & & 0.62 & & & & & & 0.55 & & \\
\hline $2 \mathrm{R} / 2 \mathrm{R}$ & 12 & $22.01 \pm N A$ & NA & & ref. & ref. & - & $28.13 \pm 3.86^{*}$ & $20.58-35.69$ & & ref. & ref. \\
\hline $2 R / 3 R$ & 18 & $19.90 \pm 2.72$ & $14.57-25.24$ & & 1.07 & $0.31-3.71$ & 0.92 & $31.02 \pm 2.93$ & $25.27-36.77$ & & 1.36 & $0.36-5.06$ \\
\hline $3 R / 3 R$ & 12 & $27.74 \pm 4.84^{*}$ & $18.25-37.23$ & & 1.57 & $0.55-4.47$ & 0.40 & $32.53 \pm 3.82^{*}$ & $25.04-40.03$ & & 1.85 & $0.59-5.84$ \\
\hline TS5utrTR & & & & 0.52 & & & & & & 0.36 & & \\
\hline A (low) & 30 & $22.14 \pm 6.77$ & $8.87-35.41$ & & 1.38 & $0.51-3.75$ & 0.53 & $32.73 \pm 4.02$ & $24.86-40.60$ & & 1.66 & $0.55-4.97$ \\
\hline B (high) & 12 & $27.74 \pm 4.84^{*}$ & $18.25-37.23$ & & ref. & ref. & - & $32.53 \pm 3.82^{*}$ & $25.04-40.03$ & & ref. & ref. \\
\hline rs16430del & & & & 0.75 & & & & & & 0.47 & & \\
\hline$-/-$ & 7 & $25.12 \pm 5.51^{\star}$ & $14.33-35.91$ & & ref. & ref. & - & $34.00 \pm 2.83^{*}$ & $28.45-39.56$ & & ref. & ref. \\
\hline$+/-$ & 16 & $22.14 \pm \mathrm{NA}$ & NA & & 0.69 & $0.19-2.47$ & 0.57 & $39.15 \pm 5.98$ & $27.42-50.86$ & & 0.40 & $0.09-1.83$ \\
\hline +/+ & 19 & $22.01 \pm 9.38$ & $3.63-40.39$ & & 0.74 & $0.30-1.84$ & 0.52 & $32.73 \pm 9.46$ & $14.20-51.26$ & & 0.88 & $0.35-2.24$ \\
\hline $\begin{array}{l}\text { rs16430del_ } \\
\text { both }\end{array}$ & & & & 0.70 & & & & & & 0.23 & & \\
\hline 0 & 35 & $22.14 \pm 7.45$ & $7.54-36.74$ & & 1.27 & $0.37-4.30$ & 0.70 & $32.73 \pm 4.48$ & $23.95-41.51$ & & 2.38 & $\begin{array}{l}0.55- \\
10.33\end{array}$ \\
\hline 1 & 7 & $25.12 \pm 5.51$ & $14.33-35.91$ & & ref. & ref. & - & $34.00 \pm 2.83^{*}$ & $28.45-39.56$ & & ref. & ref. \\
\hline
\end{tabular}

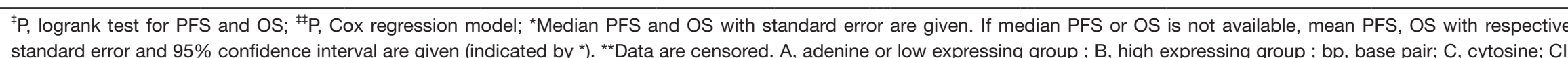

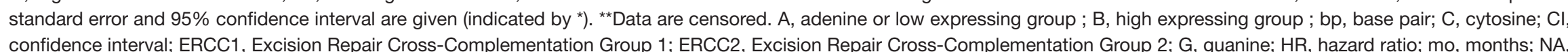

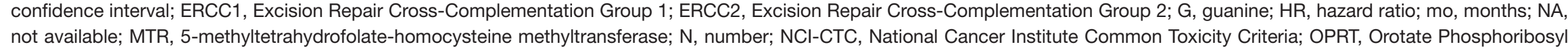
Transferase; PFS, progression-free survival; OS, overall survival; pCR, complete pathological response; \pm SE, rate \pm standard error; ref, reference; SNP, single nucleotide polymorphism;
T, thymine; TSSutrdel, thymidylate synthase: 6 -bp-deletion in the in the 3 ' untranslated regulatory region; TS5utr tandem repeat, thymidylate synthase: 28 -bp-tandem repeats in the 5 ; untranslated region; UMPS, uridine monophosphate synthetase; XRCC1, X-Ray Repair Complementing Defective Repair in Chinese Hamster Cells 1. 